Portland State University

PDXScholar

Fall 1-23-2014

\title{
Characteristics of Spoken and Written Communication in the Opening and Closing Sections of Instant Messaging
}

Kenta Nishimaki

Portland State University

Follow this and additional works at: https://pdxscholar.library.pdx.edu/open_access_etds

Part of the Interpersonal and Small Group Communication Commons, and the Other Communication Commons

Let us know how access to this document benefits you.

Recommended Citation

Nishimaki, Kenta, "Characteristics of Spoken and Written Communication in the Opening and Closing Sections of Instant Messaging" (2014). Dissertations and Theses. Paper 1548.

https://doi.org/10.15760/etd.1547

This Thesis is brought to you for free and open access. It has been accepted for inclusion in Dissertations and Theses by an authorized administrator of PDXScholar. Please contact us if we can make this document more accessible: pdxscholar@pdx.edu. 
Characteristics of Spoken and Written Communication in the Opening and Closing

Sections of Instant Messaging

by

Kenta Nishimaki

A thesis submitted in partial fulfillment of the

Requirements for the degree of

\author{
Master of Arts \\ in \\ Japanese \\ Thesis Committee: \\ Suwako Watanabe, Chair \\ Patricia J. Wetzel \\ Emiko Konomi
}

Portland State University

2013 


\begin{abstract}
This study examines opening and closing segments in instant messaging (IM) and demonstrates how openings and closings differ between oral conversation and instant messaging as well as the factors that account for the difference. Many researchers have discussed the differences and similarities between spoken and written languages. Tannen (1980) claims that spoken and written languages are not distinct categories and there is a continuum between them. She also holds that interpersonal involvement is one of the factors that determine if a particular communication is closer to spoken communication or written communication.
\end{abstract}

I will analyze IM, which is best thought of as a communication mode that resides in the middle of the continuum between spoken and written language. Beißwenger (2008) studied the turn-taking of IM and argued that contributions to instant message dialogues are achieved as individual tasks rather than through interactions between participants. He holds that the nature of the individual tasks provides the most important characteristic which distinguishes IM from oral conversation.

Closings in IM were studied by Raclaw (2008), who found two patterns of closing: one is an expanded archetype closing which is similar to oral conversation, and the other is a partially automated closing which is totally different from oral conversation because an automated message terminates the conversation. He did not discuss the characteristics underlying the two patterns of closing in instant messaging. I reanalyzed the argument by Raclaw utilizing a segment of instant messaging from my data, and discovered that what characterize the two patterns of closing in instant messaging are the 
nature of interpersonal involvement and the nature of the individual tasks. These reflect the characteristics of spoken and written communication respectively.

In this study it was found that characteristics of IM communication fluctuate between spoken and written communication. Instant messaging resides in the middle of the spoken and written continuum, but whether it exhibits characteristics of spoken or written communications can vary depending on the way participants contribute to the conversation. 


\section{DEDICATION}

This thesis is dedicated to my family for their endless love and support.

Mom and Dad, thank you very much. And I love you. 


\section{TABLE OF CONTENTS}

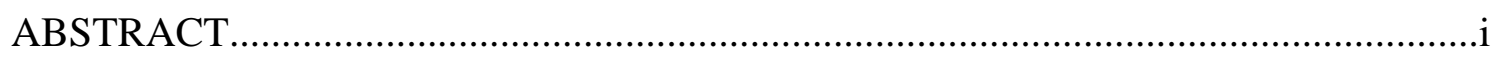

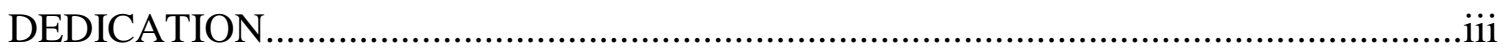

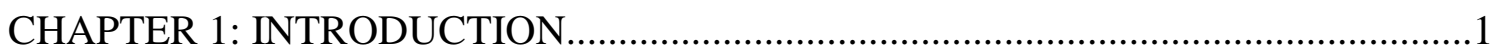

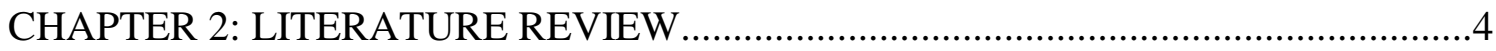

2.1. Continuum between Spoken Language and Written Communication

2.1.1. Differences between Spoken and Written Communication

2.1.2. Mixed Modes of Spoken and Written Communication

2.1.3. Interpersonal Involvement

2.2. Instant Messaging

2.2.1. The Definition of IM

2.2.2. Characteristics of IM

2.2.3. Comparison Among Spoken/Written Communication and IM

2.3. Conversation Analysis

2.3.1. The Turn-taking System in Oral Conversation

2.3.2. Adjacency Pairs in Oral conversation

2.3.3. The Turn-taking System in IM

2.3.3.1. Roles of Participants in IM

2.3.3.2. Turn Constructional Components in IM

2.3.3.3. Turn Allocational Components in IM

2.3.3.4. Phantom Adjacency Pairs in IM

2.3.4. The Turn-taking System in IM as Individual Tasks

2.4. Openings in Oral Conversation

2.5. Closings in Oral Conversation

2.5.1. Archetype Closings

2.5.2. Varieties of Closings

2.5.2.1. Pre-closings with a Closing Implicative Environment

2.5.2.2. Re-openings: Minimal and Drastic Movement out of 


\section{Closing}

2.6. Two Patterns of Closing in IM

2.6.1. The Expanded Archetype Closing

2.6.2. The Partially Automated Closing

CHAPTER 3: DATA ANALYSIS AND DISCUSSION.

3.1. Closing in IM

3.2. Opening in IM

3.3. Continuum Among Spoken, IM and Written Communication

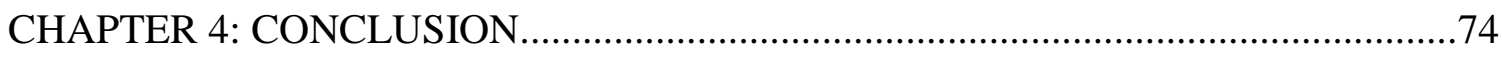

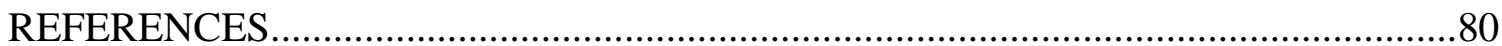




\section{CHAPTER 1: INTRODUCTION}

In recent years, communication technology has been developing rapidly and instant messaging (IM) is one of the novel modes of communication which has become widely used. Communication through IM is well studied (Beißwenger, 2008; Cristal, 2001; Garcia \& Jacob, 1999; Jettka, 2009; Raclaw, 2008), and those investigating it claim that IM has many characteristics which are not observed in other types of written (or typed) communications, although it has many features that are similar to those of spoken communication.

Before IM became an object of linguistic study, many researchers were involved in discussions involving the differences between spoken and written languages (Akinnaso, 1982; Chafe, 1982). At times it even appeared as though written and spoken languages were discreet forms of communication, but Tannen (1980) claims that spoken and written languages are not separate categories and that there is a continuum between them. Some written communication modes have many of the characteristics of spoken language and vice versa. Tannen also argues that interpersonal involvement is one of the factors that determines whether certain communications are closer to spoken communication or written communication. Chafe and Tannen (1987) provide examples of different communication modes that lie between spoken and written language. For example, formal spoken lectures, papers read at scholarly conferences, interpersonal letters, and similar communications were termed by Heath (1986) to occupy the "middle group" of the continuum. 
In my thesis I will analyze IM, which is best thought of as a communication mode that resides in the middle of the continuum between spoken and written language. I will apply Conversation Analysis (CA) to analyze IM. CA was originally developed in the 1970s and its goal was to "explore the possibility of achieving a naturalistic observational discipline that could deal with the details of social action rigorously, empirically and formally" (Schegloff \&Sacks, 1973, pp. 289-290). It was also aimed at uncovering the underlying mechanisms which enable conversation participants to achieve interactional organization and order (Seedhouse, 2004, p. 12). CA researchers have investigated varieties of interactional organizations, including turn-taking, opening and closing, and adjacency pairs.

Much of the CA research on turn-taking, opening, closing, and adjacency pairs has focused on spoken communication, but a few researchers have applied these notions to IM. In his study of IM, Raclaw (2008) found two patterns of closing: one was similar to oral conversation and the other was significantly different from oral conversation. Beißwenger (2008) studied the turn-taking of IM and argued that contribution to an instant message dialogue is achieved as an individual task rather than through an interaction between participants. Beißwenger argues that the notion of turn-taking is not fully applicable to IM because turn-taking is not interactional in IM. If Beißwenger's claim is valid, the form of the opening and closing communications, where interactional nature is clearly apparent in oral conversation, will exhibit different features in IM.

I will analyze an opening and a closing as examples of IM conducted in Japanese. These data were collected for my research paper in a graduate level course. Taking 
Beißwenger's argument into consideration, I anticipate that I will discover differences between the openings and closings used in oral conversation and those used in IM. Thus, the primary research question of this thesis is: How are openings and closings different between oral conversation and IM and what factors account for the differences? I will demonstrate how the nature of individual tasks and interpersonal involvement make clear the differences in the openings and closings that are used in IM and in oral communication. Even though the quantity of my data is limited, my findings in this study open up many questions on ways in which IM is similar to and different from spoken and written communication, and will also reveal whether or not the notion of turn-taking in oral conversation is applicable to IM. 


\section{CHAPTER 2:}

\section{LITERATURE REVIEW}

In the literature review section, I will first discuss previous research on spoken and written language and will include the differences between them and evaluate the continuum framework that captures mixtures of the two communicative modes. I will also cover the concept of interpersonal involvement as elucidated by Tannen (1982). Second, I will present the definition and the characteristics of IM. Third, I will discuss the approach of conversation analysis with a focus on how it is utilized to evaluate turntaking, adjacency pairs, and opening and closing.

\subsection{Continuum of Spoken Language and Written Communication}

This section will involve a discussion of how spoken language, IM and written language exist as a continuum. First, I will summarize the ongoing discussion involving the differences between the spoken and written languages.

\subsubsection{Differences between Spoken and Written Communication}

Discussions on spoken and written communication modes date back to the1960s. At that time the Chomskian view on linguistics was dominant, and most specialists believed that "ordinary talk could not be the object of study for linguistics since it is too disordered; it is an essentially degenerate realization of linguistics competence" (Hutchby \& Wooffitt, 1998, p. 22). Thus spoken communications were not studied. As recording technology improved, researchers became able to record conversations and analyze them. Schegloff \& Sacks (1973) discovered that, contrary to the Chomskian view, oral 
conversations were not disordered, but rather were systematically organized. Researchers such as Akinnaso (1982) started to study spoken communication as well as written communication. Akinnaso pointed out that there were two prominent views about these communication modes. The traditional view stressed the fact that speech and writing were grammatically the same even though they had slight lexical differences. The second view held that speech and writing were relatively autonomous and the two modes were considered to be quite different. Akinnaso (1982) considers spoken and written language to be different. He notes that his study "has been concerned largely with the nature of these distributions, with how and why spoken and written language differ" (Akinnaso, 1982, p. 119). He mentions the latest studies and states that while some researchers study the differences and similarities between spoken and written language, the main thrust of these studies is nevertheless on the differences between spoken and written language.

Chafe (1994) introduces six differences between spoken and written language: evanescence versus permanence and transportability, differences in tempo, spontaneity versus deliberate working over, richness of prosody, naturalness, and situatedness versus desituatedness. I will look at each characteristic briefly.

Evanescence of spoken language refers to its nature of "rapid fading" that was first identified by Hockett (1960). This is an unavoidable consequence of spoken language stemming from the nature of sound. Sound fades very quickly and it cannot be heard from afar. These qualities of sound make spoken language available only at the time and the place it is uttered unless it is recorded. On the other hand, we can read books 
from all over the world and even books from hundreds of years ago. Chafe thereby characterizes written language as permanent and transportable.

Difference in tempo refers to the fact that speaking is usually delivered faster than the written language is produced. Chafe states that this is due to a purely mechanical reason. Writing is slower than speaking because we have no technological device which allows us to write as fast as we speak.

Spontaneity refers to the nature of spoken language wherein it tends to be delivered without careful thought about the content. To borrow Chafe's phrase, ideas tend to be activated "off the top of one's head" (Chafe, 1994, p. 43). Since speakers produce utterances off the top of their head, their utterances tend to be fragmented and disorganized. On the other hand, writers usually have the opportunity to look over their work and to alter its content. As a result, writers can easily produce longer and more complicated sentences as compared to their everyday speech.

Richness of prosody means that we can utilize pitches, prominences, pause and voice quality when we speak. On the other hand, our writing systems do not have well developed ways to express prosodic phenomena.

Naturalness refers to the idea that spoken language is physically natural to the human organism while writing is not. We can speak without the need for any tool while we cannot write if we do not have something to write with and on.

Lastly situatedness and desituatedness refer to the setting in which communication takes place. Those engaged in conversation are typically physically close when they speak while the writer and the reader do not have to be close when the writer 
constructs and produces a text. Chafe holds that copresence and immediacy of interaction are important elements in situatedness. Without support from technical devices, participants in a conversation have to be present at relatively nearby locations in order to hear each other's voice.

In addition to Chafe's (1994) six characteristics, other researchers have discovered numerous additional differences. Much of the research on spoken and written communication up to the mid 1970s focused on the differences between the two communication modes. However as the differences of spoken and written communications are discovered, it is also pointed out that there are many communication modes which have features of both spoken and written communication. Tannen (1982) does not hold that spoken and written communications are distinctly different categories, but she views the two modes in terms of a continuum. She claims that interpersonal involvement is an important aspect of whether a communication mode is similar to the spoken or written language.

\subsubsection{Mixed Modes of Spoken and Written Communication}

After much research was done to reveal the differences between the spoken and written language, some researchers began to view the differences in terms of a continuum between the spoken and written language (Chafe, 1982; Tannen, 1982). Tannen (1982) supports the concept of such a continuum, and holds that some features of spoken language can appear in written language, and vice versa. Many communication modes have features of both spoken and written language. According to Chafe \& Tannen (1987), 
formal spoken lectures, personal letters, diaries, notes passed in class, computer dialogue, oral ritual, oral poetry, and other similar communications are examples of communications which are somewhere between the spoken and written language. These modes are what Hearth (1986) calls "middle groups of the continuum."

To illustrate an example involving the middle group of the continuum Tannen (1988) described a situation in which a paper written by her was read aloud by another scholar at a symposium. She pointed out that even though the genre "giving a paper" clearly had many features of the spoken language, since the paper was delivered through speech, it also had features of the written language. For example, the paper was planned and written carefully, which is one of the features of written language. The importance of Tannen's argument is that it clearly indicates that there is no dichotomy between the spoken and written language and that rather, they exist as part of a continuum. While each of the two communicative modes definitely has its distinct features, it is equally clear that there is a continuum between them and some genres may exhibit features of both spoken and written communication. Some communicative acts, whether spoken or written, will exhibit many features of the spoken language while others may not.

\subsubsection{Interpersonal Involvement}

Tannen has done extensive research in the continuum between spoken and written communication modes and claims that interpersonal involvement is one of the factors that determines if certain communication is closer to spoken communication or written communication. At the same time, written discourse is characterized by less focus on 
involvement and more focus on the information conveyed. Tannen (1982, p. 2) states that interpersonal involvement reflects the speaker's stance toward the audience, material or content. In addition, the notion of interpersonal involvement is a dimension deeper than the surface feature of linguistic structure. Thus, interpersonal involvement can be observed as existing under the more obvious surface characteristics of spoken language. In her review she notes that two major hypotheses have emerged: the Contextualization Hypothesis and the Cohesion Hypothesis (Tannen, 1985). She holds that these two hypotheses can be combined with the single notion of interpersonal involvement.

According to Tannen (1985), the Contextualization Hypothesis characterizes spoken discourse as highly context bound and written language as decontextualized. When we speak we are aware of the general context which both the speaker and hearer share. By sharing the same context, the speaker can be minimally explicit and the hearer can ask for clarification when necessary. Also, they often share a social background so it is typically easy to understand each other. In contrast, a writer and a reader may not share context and usually exist in a different time and space. In addition, they often share minimal social backgrounds. Therefore, a writer has to provide as much background information as possible because readers cannot ask for clarification. For example, an old couple who has lived in the same house for a long time share much social background so when they talk to each other they do not need to express everything explicitly. They can infer many things from minimal lexical information by utilizing their shared background. In contrast, if a reader in the present day reads a book by an unknown author written long ago, the reader and writer share minimal background. Contemporary readers and the 
authors in the past inhabit different times and possibly different places. Readers have to rely on the text as they possess little background knowledge from which they can draw inferences. At the same time, if authors want readers in the future and/or in different places to fully understand their writings, they have to be as explicit as possible. These are extreme examples, but the categories are not always clear and there are communication modes that fall in the middle of the two extremes. For example, private letters to friends or family are written communication, but the participants often know each other and typically share social backgrounds. They also know what is happening in each other's lives so they do not need to explain everything in the text. Thus there are also mixed modes in this writing.

Casual conversation (context-focused) and expository prose (message-focused) are considered to be the typical modes of spoken and written language, because casual conversation shares maximum context while expository prose for readers shares minimum context. Tannen states that casual conversation and expository prose (messagefocused communication) are often associated with spoken and written language as follows:

There is something typically written about message-focused communication, for it is the innovation of print that made it common to communicate on a large scale with others who are not in one's immediate context. And there is something typically oral about interpersonal involvement. In communication with others with whom one has a close social or personal relationship, it is hard to focus on 
information exclusively, because the importance of the relationship is too keenly felt to be ignored. (Tannen, 1985, p. 129)

In sum, the Contextualization Hypothesis postulates that the degree to which a certain communication mode is close to spoken or written communication depends on how much context a speaker/writer and a hearer/reader share. In addition, Tannen claims that the Contextualization Hypothesis can be included in the notion of interpersonal involvement because the degree of shared context also determines the extent to which they are involved in the interaction.

The second hypothesis is the Cohesion Hypothesis, which examines how cohesion is achieved by utilizing the degree to which a certain communication mode is close to spoken or written communication. The notion of cohesion was originally developed from the analysis of written discourse by Halliday \& Hasan (1976). Cohesion is a factor that indicates whether a text is connected well or merely a bundle of unrelated sentences. Cohesion is achieved by various linguistic elements such as conjunctions and pronouns which indicate how the texts are semantically interrelated. Tannen (1985) reviewed studies on how cohesion is achieved in both written and spoken discourse (Chafe, 1982; Gumperz et al., 1984). She states: "in spoken discourse, cohesion is accomplished through paralinguistic and prosodic cues, whereas in written discourse cohesion must be lexicalized" (Tannen, 1985, p. 130). This means that in spoken discourse speakers can use paralinguistic and prosodic cues such as pitch, tone of voice, 
speed of utterances, and expressions on their face to indicate relationships among ideas and highlight the importance of particular contents.

There is also middle group of spoken and written continuum in this regard. For example, non-lexical features such as capitalization and quotation marks are used to create emphasis in written communications and readers can infer meaning from them. In this way, writers can use paralinguistic cues and readers can infer the writer's attitude toward the content so that they can establish cohesion with non-lexical items, but such cues still have to be written down. Hence written communication using such paralinguistic cues are considered to be mixed modes of spoken and written communication.

The Cohesion Hypothesis can be included in interpersonal involvement as was the Contextualization Hypothesis. A great deal of information is conveyed by nonverbal or paralinguistic elements in face-to-face conversation. Therefore, Tannen (1985, p. 131) states that the listener has to fill in the information that is not overtly stated. For example, listeners may have to deduce speaker's emotion from voice quality or they may have to utilize prior experience and background knowledge to make sense of the entire set of information that is being communicated. All of this cannot be done if the listener is detached and not closely involved with the conversation. In contrast, written discourse is message-focused and non-verbal and paralinguistic elements are not available. Even though authors have a variety of ways to compensate for the lack of non-verbal and paralinguistic elements, such as using emoticons or exclamation marks, these symbols have to be written down. All information is embedded in the text and the reader and 
writer do not have to be personally involved with each other. ${ }^{1}$ Therefore, the Cohesion Hypothesis can also be subsumed under the notion of interpersonal involvement.

Hence, Tannen claims that interpersonal involvement underlies both the

Contextualization Hypothesis and the Cohesion Hypotheses: What we call features of the spoken language involves a relative focus on interpersonal involvement and what we call features of the written language entails relatively less focus on interpersonal involvement and more focus on the information. ${ }^{2}$

\subsection{Instant Messaging}

Many researchers have found that communication using computer technology is different from other spoken and written communication modes. Halliday (1985) argues that modern technology further blurs the distinction between spoken and written language. Crystal (2001, p. 238) states "[computer-mediated communication is] something fundamentally different from both writing and speech, as traditionally understood." Such comments resemble similar claims regarding the difference between spoken and written languages. Some say that the two communication modes are totally different and should be treated as different languages. Similar to the continuum between

\footnotetext{
${ }^{1}$ In cases of personal letters, the writer and the reader are personally involved more than impersonal letters. Therefore, personal letters can be placed closer to spoken communication on the continuum between spoken and written communication.

${ }^{2}$ In more recent research, Tannen started to use the notion of "poetic" to refer to the features of spoken language (Tannen, 1997; Tannen, 1992). Since what she calls "poetic" and "involving" involve basically the same ideas, poetic might be misleading in my research because I focus more on the turn-taking system of each communication mode rather than the paralinguistic and prosodic elements. I will use involvement to refer to what Tannen currently refers to as "poetic."
} 
spoken and written language, however, other researchers hold that there is also a

continuum between spoken language, computer-mediated language and written language.

Marques (2008) is one of those who claim that email is somewhere between the

spoken and written language. She utilized Eggins (2004)'s analysis of spoken and written

languages ${ }^{3}$ to analyze email from students to their teachers. Marques (2008) compared

the characteristics of the emails to evaluate her claim that email shares characteristics of

both spoken and written language and that email resides in the continuum between

spoken and written language. Considering Marques's research and Tannen's discussion

on spoken and written language, I will not treat spoken/written languages and computer-

mediated communication as completely different communication modes. I will adopt the

view that they are not distinct categories, but rather that they are part of a continuum.

\subsubsection{The Definition of IM}

It is very difficult to define IM because it is still developing very quickly and its conventions are changing rapidly. Nardi et al. (2000) describes IM in the following way:

IM is near-synchronous computer-based one-on-one communication. With a fast network, transmission times are fractions of a second and the experience is of near-synchronous interaction. Like chat, IM allows users to type messages into a

\footnotetext{
${ }^{3}$ Eggins (2004) analyzes spoken and written language with eight elements. She claims that spoken language is characterized by a turn-taking organization, context dependency, dynamic structures, spontaneity phenomena, everyday lexis, non-standard grammar, grammatical complexity and lexical sparsity. Conversely, written language is characterized by monologic organization, context independency, synoptic structure "final draft" (polishment), indications of earlier drafts removed, "prestige" lexis, standard grammar, grammatical. simplicity, and lexical density
} 
window, but like the phone, it is based on a dyadic "call" model. Users do not go into "rooms" to converse with whomever is there; instead there is a single individual with whom they communicate (although they may have several concurrent dyadic conversations with different individuals in progress at a given time). (Nardi et al., 2000, p. 80)

Thus, they hold that the important feature of IM is that it is near-synchronous computer-based one-on-one communication. It is different from computer-based "chat" in that the IM users do not go into a specific virtual space, which is called a "room" where the chat user can have chats with many people. In this regard IM is similar to a phone call because we communicate with one or more selected individuals at a time. The above definition is not completely precise when we look at present-day IM because conventions for this type of communication are still changing. For example, Skype is one of the best known social networking systems and it also has an IM system. Unlike the IM available in Nardi et al.'s time, in today's IM one can select multiple people as receivers of a message even though one-on-one communication is still prevalent. In addition to this, some types of IM can send voice mail very easily (LINE and Skype). As we can see from these examples, IM is changing gradually even now and it is very difficult to define what instant message is. The IM I will analyze in this paper is the IM system in Skype. With it a user can send a message to either one or multiple receivers. In addition to this, a user can send emoticons which one can select from a set of options with just one click. Thus for the purpose of analyzing my data, I will define IM 
as: near-synchronic computer-based communication which enables users to exchange messages in typed text including emoticons to either individuals or multiple parties.

\subsubsection{Characteristics of IM}

This section discusses the characteristics of communication through IM. There are some characteristics that are unique to IM and there are also characteristics that are similar to spoken and written languages. Jettka (2009) discusses characteristics of IM which are not observed in spoken and written languages in terms of lexis, grammar, orthography, and turn-taking. In this section, I will discuss lexis, grammar, and orthography as turn-taking will be discussed in the section on turn-taking in the theoretical framework of Conversation Analysis.

First, Jettka (2009) claims that the use of special expressions including emoticons such as facial expressions including ":-)" and ":-(" causes the peculiar look of IM and it may be the most apparent feature of IM. In addition to this, Lee (2005) sees alteration of spellings as an important characteristic of IM. For example, "boi" for "boy," and "dunno" for "don't know" are examples of alternative spelling. Users also omit some letters as in "nothin" rather than "nothing" and "goin" rather than "going." These characteristics can be observed in other written discourse, but are more common in IM.

Jekkta (2009) also found the grammar of IM different from other communication modes. Jekkta states that grammar in IM does not correspond to grammar in academic writing, but it is very similar to colloquial style. In addition, Crystal (2001) states that omission of copular verbs and auxiliary verbs, and non-standard concord between subject 
and verb are grammatical characteristics of IM. He gives "i fine", "me is 31 " and "you feeling better now?" as examples of the grammatical characteristics of IM.

Lastly, Jekkta (2009) discusses characteristics of IM in terms of orthography. For example, he argues that because of the lack of prosody and sound level in IM, users employ upper case exclamations. Users can make sentences more emotional using upper case in addition to exclamation marks such as “HEY!!!!!.” Additionally, Crystal (2001) argues that capitalization is regularly ignored, even for "I." Jekkta claims that this is a result of time pressure to write quickly and this is a strategy for making typing more efficient. In addition to these unique characteristics, there are also features of IM which are similar to both spoken or written languages.

\subsubsection{Comparison Among Spoken/Written Communication and IM}

There are many researchers who study the comparison among spoken communication, written communication and IM using their own frameworks (Lee, 2005), and they claim that IM has characteristics of both spoken and written languages. I will use Chafe's (2004) discussion on the characteristics of spoken and written languages to compare IM and spoken, written language as one of the examples.

IM is clearly a type of written language since the message is conveyed by written (or typed) words. However, it exhibits characteristics of spoken language identified by Chafe (1994). First, IM is similar to spoken language in terms of tempo. As Isaacs et al. (2002) claim, conversations in IM are brief, or fragmented in Chafe (1994)'s term, and IM is often used to address a single purpose. Therefore interactions in an IM context tend 
to be very quick. Second, because of the quickness of interaction in IM, messages tend to be produced spontaneously rather than after working the phrases over for a long period of time. Third, interactions in IM are more situated than in other written discourse such as expository prose. Compared to expository prose, the interlocutors usually know each other and share the same context even though they are not physically facing each other. In terms of these three characteristics it can be concluded that IM has many characteristics of the spoken language.

However, the other three characteristics of written language, permanence and transportability, unrichness of prosody, and unnaturalness, are applicable to IM as well. Permanence and transportability apply to IM because once we type something it will exist until it is deleted and it is transportable if the device is movable. Richness of prosody in IM might be controversial because we can express prosody in various ways, for example by using emoticons, exclamation marks, and capitalization, but it has not reached the richness of spoken language. IM is not "natural" because we need the internet to use IM. Therefore IM is considered to have the characteristics of both spoken and written languages and can be placed in the middle of a continuum between them.

Thus far, I have discussed general characteristics of spoken/written languages and IM, and showed that IM has characteristics of both spoken and written languages placing it between the two ends of the spoken and written continuum. In the next section I will present conversation analysis as a linguistic approach to analyzing language and communication along with the notions of turn-taking and adjacency pairs. 


\subsection{Conversation Analysis}

This section will discuss conversation analysis (CA), which is a crucial tool of my research. The use of CA facilitates an analysis of the differences between oral communication and IM. Two of the essential notions of CA involve the turn-taking system and adjacency pairs. These concepts will be discussed from the perspective of oral conversation as well as from perspectives derived from the research on IM.

\subsubsection{The Turn-taking System in Oral Conversation}

The turn-taking system of oral conversation is demonstrated in an article by Sacks, Schegloff \& Jefferson (1974). According to these authors, the turn-taking system for oral conversation can be described in terms of two components, which are the turnconstructional component and the turn-allocational component, and a set of rules. The turn-constructional component refers to turn-constructional units that are minimal units out of which a turn can be formed. They are constructed with various types of units: sentence, clause, phrase and lexical constructions. The following excerpt contains examples of unit-types:

\section{[Excerpt 1]}

(1) A: Uh you been down here before

(2) B: havenche. $\mathrm{Yeh}^{4}$

\footnotetext{
${ }^{4}$ This unit-type is produced at the same time as A's "havenche." Therefore it is not really true that "Yeh" is produced 'after' A's unit-type. Sacks, Schegloff \& Jefferson (1974) regard this concurrence of unit-type overlapping. Though I will not go in depth on 
(3) A: Where the sidewalk is?

(4) B: Yeah,

(5) A: Whur it ends,

(Sacks, Schegloff \& Jefferson, 1974, p. 103)

In this short excerpt from a conversation, we can see several examples of unittypes. The first utterance "Uh you been down here before havenche" (1) is a sentential unit-type because it is a complete sentence. The other two utterances of A's can be regarded as phrasal unit-types. Both of B's utterances are lexical unit-types because they consist of just the lexical items of "Yeh" (2) and "Yeah" (4). In this way each utterance is considered to be a unit-type.

Sacks et al. also note that "the possible completion of a first such unit constitutes an initial transition-relevance place" (ibid., p. 703). Transition-relevance places are where transfer of speakership or speaker-change may occur. After a speaker produces one of these unit-types, there is a chance that a speaker, including both the current and a different speaker, will produce another unit-type.

The other component is the turn-allocation component. These encompass options for allocating turns among participants. Sacks, Schegloff \& Jefferson (1974, p. 703) state that there are two groups of turn-allocational techniques: (a) those in which the next turn is allocated by the current speaker's selecting the next speaker and (b) those in which the

overlapping, as it is not the focus of this paper, they state that though overlapping is common, it is much more common for one party to speak at a time. For more discussion on overlapping, refer to Sacks, Schegloff \& Jefferson (1974, pp. 706-708). 
next turn is allocated by self-selection. Turns are constructed with unit-types. After finishing one unit-type, the current speaker chooses who will produce the next unit-type or another speaker will self-select him/herself at the transition-relevance place.

In addition to the two components, the turn-constructional component and the turn-allocation component, there are also rules governing how these components are used in turn-taking according to Sacks, Schegloff \& Jefferson (1974) who state that the following set of rules govern turn-taking.

(1) For any turn, at the initial transition-relevance place of an initial turnconstructional unit:

(a) If the turn-so-far is so constructed as to involve the use of a 'current speaker selects next' technique, then the party so selected has the right and is obliged to take next turn to speak; no others have such rights or obligations, and transfer occurs at that place.

(b) If the turn-so-far is so constructed as not to involve the use of a 'current speaker selects next' technique, then self-selection for next speakership may, but need not, be instituted; first starter acquires rights to a turn, and transfer occurs at that place.

(c) If the turn-so-far is so constructed as not to involve the use of a 'current speaker selects next' technique, then current speaker may, but need not continue, unless another self-selects.

(2) If, at the initial transition-relevance place of an initial turn-constructional unit, neither la nor $\mathrm{lb}$ has operated, and, following the provision of lc, current speaker has continued, then the rule-set a-c re-applies at the next transition-relevance place, and recursively at each next transition-relevance place, until transfer is effected.

(Sacks, Schegloff \& Jefferson, 1974, p. 704)

While these rules appear quite complicated, the overall principles of turn-taking are as follows: A current speaker may or may not choose the next speaker. If the current speaker chooses the next speaker, s/he will provide the next unit-type. If the current 
speaker does not, another speaker may self-select him/herself. If nobody self-selects, the current speaker will continue.

\subsubsection{Adjacency Pairs in Oral Conversation}

Understanding adjacency pairs is essential to the study of turn-taking, opening, and closing. According to Seedhouse, adjacency pairs are "paired utterances such that on production of the first part of the pair (e.g., question) the second part of the pair (answer) becomes conditionally relevant" (Seedhouse, 2004, p. 17). As Seedhouse states, one of the common examples of an adjacency pair is a question and answer sequence. When we ask a question of a listener, an answer to the question is expected soon after in the interaction. The second part of an adjacency pair is so important that if it is not provided, it is treated as noticeably absent and the absence can become the object of remedial efforts or a justifiable negative inference (Schegloff, 1968). In many cases, the second pair part immediately follows the first pair part, but it is not always the case. In the next excerpt, one adjacency pair is embedded in another adjacency pair.

\section{[Excerpt 2]}

(1) A: May I have a bottle of Mich? Q1

(2) B: Are you over twenty-one? Q2

(3) A: No. A2

(4) B: No. 
A's Q1 “May I have a bottle of Mich?" asks a question so an answer is expected from B soon after. However, instead of providing an answer, B asks a question with Q2 “Are you over twenty-one?" to make sure of A's age. In response to B's question, A provides the answer "No" (A2), so Q2 and A2 together comprise an adjacency pair. After A2, B finally provides an answer "No" to A's initial question, "May I have a bottle of Mich?” (Q2). Therefore, the adjacency pair involving Q2 and A2 is embedded in the other adjacency pair comprised of Q1 and A1.

However a participant cannot randomly utter the second part of an adjacency pair. B's Q2 “Are you over twenty-one?" is important and relevant to A's Q1 "May I have a bottle of Mich?" because they cannot sell Mich to a minor and B has a justifiable reason to ask a question instead of providing an answer. In contrast, in the next excerpt [3], an answer to a question is not provided immediately after a question, making the questioner A seemingly uncomfortable as the second part of the adjacency pair noticeably absent.

\section{[Excerpt 3]}

(1) A: is there something bothering you or not?

(2) B: (pause 1.0)

(3) A: yes or no

(4) B: (pause 1.5)

(5) A: eh?

(6) B: no.

(Atkinson and Drew, 1979, p. 52) 
A asks a first question "is there something bothering you or not?" in (1) and that question is the first part of an adjacency pair, so in normal circumstances, an answer is anticipated soon after as the second pair part. But B does not answer the question for one full second. So A asks another question "yes or no" in (3) but B does not provide an answer either. In response to A's “eh?" in (5), B finally says "no" in (6). A had to ask three questions to get an answer from B, and A uses increasingly curt linguistic forms. In response to B's failure to complete the adjacency pair immediately following the first question. Thus failing to provide the second part for an adjacency pair may result in unfavorable inference or the breakdown of a conversation. As shown, the concept of adjacency pairs seems to be quite simple, but it is important for moving a conversation forward smoothly.

\subsubsection{The Turn-taking System in IM}

The turn-taking system of written discourse, apart from IM, has not been a subject of study in CA, since the focus of Conversation Analysis is on conversation, just as the name of the subfield implies. Even though IM is considered primarily a written communication mode, it does appear to have a turn-taking system that is relatively similar to that of spoken communication. An excerpt from IM follows:

[Excerpt 4]

$$
\text { Lars: Hey!!! }
$$



Bianca: Hi!
Lars: $\quad$ Sorry... I just sent you email, then heard your tune, so I couldn't resist
Bianca: $\quad$ OK, will check for it. Natalie and Beth say hi.
Lars: $\quad$ Say hi to them for me!
Bianca: will do!

(Isaacs et al., 2002, p. 19)

At first glance, it seems that Lars and Bianca are taking turns in a way similar to that of spoken communication and the participants produce the next utterance at transition-relevance places just as in an oral conversation. However, many researchers claim that there are many differences between the turn-taking system of spoken communication and that of IM in terms of the participants' roles, turn construction, turn allocation, adjacency pairs, and interpersonal involvement (Beißwenger, 2008; Garcia \& Jacob, 1999; Gonzalez-Lloret, 2011; Jettka, 2009; O’Neil \& Martin, 2003). I will discuss these differences in subsequent subsections.

\subsubsection{Roles of Participants in IM}

In a discussion of the general characteristics of the turn-taking system in IM, Garcia \& Jacob (1999, pp. 346-347) note that while each participant is referred to as a speaker and a hearer in an oral conversation, participants in IM are not speaker and hearer like those in an oral conversation. Rather, they play several roles throughout the 
interaction: message constructor, message poster, waiter, reader or worker. The first four roles are quite easy to understand. They are participants who construct a message, post a message, wait for a message and read a message. A participant is considered a "worker" when $\mathrm{s} / \mathrm{he}$ is engaged in nonscreen activities, such as watching television, reading a book and having a meal. In addition to variations of the roles of the participants, the authors claim that participants in IM can play multiple roles at a given time unlike what occurs in an oral conversation. For example, a participant can wait for a message from other participants while s/he scrolls and reads previous postings. One can also construct a message while waiting for a message. This is a big difference from oral communication, in which a participant is usually either a speaker or a listener. Because participants need not be listeners while they are waiting for a message, they can engage in other activities separate from the conversation. In the next section I will discuss the turn constructional component in IM.

\subsubsection{Turn Constructional Components in IM}

Garcia \& Jacob (1999) state that turn-constructional components in IM are different from those of an oral conversation in three ways: the meaning of pauses, the location and significance of transition-relevance places, and self-repair of messages-inprogress.

Garcia \& Jacob (1999) hold that the recipient of a message experiences only silence and postings. Recipients can infer what is happening during the silence, but they do not have direct access to real-time message production. In oral conversation, silences 
and pauses are apparently noticeable and painful obstacles to English native speakers, while in Japanese conversation they are acceptable and they even build rapport between participants (Shigemitsu, 2007). On the other hand in IM, because a participant can play one of many roles, recipients may infer that the other silent participant could be constructing a message, scrolling and reading the previous post, waiting for a reply, or working on something else. The participant "cannot determine which of these activities is being engaged in at any given point" (Garcia \& Jacob, 1999, p. 353). Silences in IM are not painful nor rapport building as they are in oral conversation. Therefore silences and pauses in IM have different meanings from those in oral conversation, and the different meanings can be attributed to the differences in the nature of the participant role specific to the IM communication mode.

Transition-relevance places in IM are different from those in oral conversation because the participants in IM cannot see the message-in-progress while hearers can hear it. Thus sentences and phrases, which can be transition-relevance places in oral conversation, are not necessarily transition-relevance places in IM because message constructors can keep typing a message without interruption from other participants. Instead, completed and posted messages are considered to be transition-relevance places in IM because participants can only respond to complete posted messages. Even if a message constructor types a sentence, which is considered to be a transition-relevance place in oral conversation, other participants cannot respond to it unless it is posted. Thus Garcia \& Jacob (1999) conclude that participants in IM regard completed and posted 
messages as transition-relevance places, and consequently, transitions of turns occur after completed message is posted.

The third difference in the turn-constructional component is self-repair of messages-in-progress. According to Garcia \& Jacob (1999), message constructors can edit their messages as they write in IM before they post their message. It is true that selfcorrection can occur in oral conversation, but utterances cannot be changed because the utterances are conveyed to hearer at once. Speakers cannot delete utterances; they can only amend the meaning of their utterance afterward. However, message constructors in IM can delete a message and compose a new one before they post the message. In addition, the Garcia \& Jacob discovered that message constructors edit their message-inprogress "in response to" new messages posted while the message constructors are typing a message. Therefore they posit that the turn-construction process is an interactive process in IM. However, what they call interaction in IM is not the same as the interactive processes that occur in oral communication and there is a significant difference between them. I will discuss this in a later section when Beißwenger's argument is presented.

\subsubsection{Turn Allocational Components in IM}

Turn allocational components in IM are also different from the turn allocational components described in oral conversation. When speakers in oral conversation try to choose the subsequent speaker, they often use the first part of an adjacency pair. In IM, on the other hand, while participants use the first part of a possible adjacency pair to 
select the next speaker, the attempts often fail (Garcia \& Jacob, 1999, p. 354). This is because the intended next speaker may be reading, scrolling or writing and another participant may jump in before the intended next speaker becomes available.

Another aspect of turn allocational components in IM is that even if it seems that the current speaker successfully selects the next speaker with an adjacency pair such as question and answer, it may not always be a successful selection (Garcia \& Jacob, 1999). The authors claim that this is because of the nature of adjacency pairs in IM. They refer to apparently successful adjacency pairs as phantom adjacency pairs because the second part of an adjacency pairs might actually have been posted coincidentally. I will examine phantom adjacency pairs closely in the next section because a thorough understanding of adjacency pairs is a crucial element for the coming discussion of closings.

\subsubsection{Phantom Adjacency Pairs in IM}

Garcia \& Jacob (1999), investigating the interactional organization of IM, discovered that an apparently successful adjacency pair at the surface level can actually be a phantom adjacency pair. According to Garcia \& Jacob (1999), phantom adjacency pairs are pairs of utterances that look like adjacency pairs in form, but are actually not in terms of content. To discover this they utilized special equipment which recorded both the scripts and the actions of all the participants. The equipment allows the researcher to observe how the messages are constructed, which is often overlooked. They observed adjacency pairs in IM and concluded that the first and second parts of some adjacency pairs are just coincidental byproducts of the turn exchange system of IM (Garcia \& Jacob, 
1999, p. 305). They use the script of the IM quoted below as an example, in which Silver, Mr. White and Fred are engaged in IM.

[Excerpt 5]

(1) Silver: And you are angry that your credits did not follow you

(2) Mr. White: Is that it?

(3) Fred: $\quad$ Yes I am angry that I lost a lot of credits but thats where I fell into a hole with the first final of this paper I tended to focus in on that anger and not on the logicality of the big picture

(4) Mr. White: Ah ha

(5) Mr. White: And now you will choose to focus on the logic instead of the emotion...

(6) Silver: Okay so you need to be detached from your feelings when writing this essay... Easier said than done

(7) Fred: $\quad$ No thats not it they do have alsorts of cracks in the system that if you know how to play them you can get more credits to transfer than you could if yu did'nt know how to dodge the system

(Garcia \& Jacob, 1999, pp. 305-306)

In this script of IM, Mr. White's post "Is that it?" in (2) and Fred's post "Yes I am angry ... big picture" in (3) seem to constitute an adjacency pair because Mr. White asks a question and Fred's initial utterance "Yes" form a combination of question and answer 
at the surface level. However, the videotapes of this interaction shows that when Mr. White started constructing his question in (2), Fred already had written as far as "Yes I am angry ... I tended to focus in on that" in (3). Thus they concluded that posts (2) and (3) constitute a phantom adjacency pairs. This example has shown that question and answer normally constitute an adjacency pair in oral conversation, in IM they are not always placed next to each other. Moreover, seeming adjacency pairs in terms of form are not always adjacency pairs in terms of content.

\subsubsection{Turn-taking System in IM as Individual Tasks}

Beißwenger (2008) analyzed IM with a device which is able to trace participants' eye movement during chat. He found that turn-taking in IM is an individual task rather than a task requiring interpersonal negotiation. Beißwenger first discusses the differences between screen protocol and mental protocol, which clarifies one of the main causes of the different turn-taking system in IM. Screen protocol is the graphic protocol of exchanged text messages on the users' screens and individual mental protocol is the individual mental representation of the ongoing conversation by a particular participant (Beißwenger, 2008, pp. 2-3). Screen protocol is automatically updated whenever new messages are delivered to the users' computers by the chat server. Thus screen protocols are usually the same for all participants after a message is posted. However individual mental protocols are often different because an individual's mental protocol is updated only when s/he directs her/his gaze and attention to the screen, detects new textual 
information delivered by the interlocutors, and, by processing this information, converts it into a new item of her/his mental protocol. In this regard Beißwenger states that:

Chat participation is based on self-orientation toward the screen ... in contrast to the co-construction of turns under face-to-face conditions, the construction of contributions to a chat dialogue in progress is not an interpersonal, but rather an individual task that each participant has to manage on his/her own. (Beißwenger 2008, p. 4)

This is significantly different from oral conversation, because one of the most important characteristics of oral conversation is interpersonal involvement. It is not that IM does not involve any interpersonal involvement at all because participants do exchange messages with each other. In this respect, however, IM is indeed different from books and diaries which rarely involve responses from readers. However, IM is significantly different from oral conversation in that message constructors are completely separated from readers and thus work individually when they construct a message. When readers read messages, message constructors are not present in front of them. On the contrary, listeners of oral conversation are listening to speakers producing utterances. Even though participants in IM exchange messages, their tasks are achieved individually. Because IM and oral conversation differ in this fundamental aspect, turn-taking systems in the IM communication mode are quite different from those in the oral communication mode. Turn-taking in oral conversation requires interpersonal involvement because of the 
presence of a speaker and a listener, but participants in IM construct messages as individual tasks and post their messages whenever they want. Consequently, turn-taking in instant message is achieved as a byproduct of the sequential production of individual tasks.

The nature of the individual task in fact underlies the characteristics of the turntaking system of IM I discussed in the previous section. Self repairing in IM is a good example. Contrary to Garcia \& Jacob's (1999) claim that self repairing involves interaction, the self repairing of IM is not quite the same as that of oral communication. It is true that message constructors in IM can self-repair their message as they write while responding to another's posting. However, what message repairers can respond to is a posted message which shows only the screen protocol. As discussed earlier, the screen protocol is merely a matter of what is happening on the screen, but not in the participants' mind. Therefore message repairers can interact with another participant only indirectly on the screen. Thus, self repairing in IM is only an individual task in the response to the screen and it does not involve other participants.

Lastly, it needs to be noted that the nature of individual tasks is similar to the characteristics of the written communication mode. As Tannen (1985) states, in written communication, the message a writer wants to convey to the reader has to be written down in the text and the reader has to infer all information from the text. Writing and reading of texts are tasks achieved individually by writers and readers. This is why Kay (1977) characterized written communication as an "autonomous language." The difference between the autonomy of written communication and the nature of individual 
tasks in IM involves how often and how quickly a writer and a reader exchange messages. While technology makes IM communication almost synchronic, the notion of autonomy can be applied to IM as well. Thus, the notion of autonomy is quite similar to the nature of individual tasks in IM, and the nature of individual tasks can be regarded as one of the characteristics of the written communication mode.

Therefore, it is concluded that turn-taking in IM is significantly affected by the nature of the individual tasks. While turn-taking in oral conversation is an interaction which requires interpersonal involvement, participants in IM construct messages as individual tasks and the contribution to turn-taking is achieved individually. The nature of individual tasks is similar to the notion of autonomy, which is a characteristic of written communication. Thus the nature of individual tasks will play an important role in the discussion on the continuum among spoken, IM and written communication.

\subsection{Openings in Oral Conversation}

This section discusses how people initiate a phone call, as proposed by Schegloff (1986), and shows how important intricate turn-taking is and how participants are involved in the interaction.

Schegloff (1986) claims that there is an archetype opening which consists of four sequences: the summons/answer sequence, an identification (and/or recognition) sequence, a greeting sequence, and one or more howareyou (How are you?) sequences. In the first sequence (summon/answer sequence), the caller makes a call and the answerer's phone will ring. The act of picking up a phone does not always indicate that the person 
who answered the call is ready to talk. For example, the answerer's mouth may be full of food, and s/he may not be ready to talk. Thus, in addition to picking up the phone, an answerer must provide a simple greeting phrase to tell the caller that the answerer is ready to talk. The second sequence is an identification/recognition sequence where the person identifies who is calling and answering. It usually happens that they recognize the other participant by his/her voice. If they do not, they can ask for identification of the other person in this sequence. The third and fourth sequences are the greeting and howareyou sequences, where participants greet and ask about the general condition of the other participant. In addition to these four sequences, it must be noted that the all sequences consist of adjacency pairs. The excerpt [6] below is a common type of opening which consists of the four sequences.

\section{[Excerpt 6]}

(1) ring
A: Hello::

C: H'llo, Clara?

A: Yeh,

C: $\quad$ Hi Bernie.

A: $\quad$ Hi Bernie.

C: How're you.

A: I'm awright.

How're you. (summons/answer sequence)

(identification/recognition sequence)

(greeting sequence)

(howareyou sequence) 
(9) C: Okay::?

(10) A: Good.

(11) C: Laura there? (first topic)

$(\mathrm{A}=$ Answerer and $\mathrm{C}=$ caller $)$

(Schegloff, 1986, p. 115)

While there are many exceptions to these basic sequences, Schegloff found the four sequences so often that he considered them as basic components for opening a phone call by Americans. Schegloff (1986) also observed that some openings are more compressed than the archetype opening and may consist of fewer than the four core sequences. This shorter opening allows the conversation to be more efficient and thus allows speakers to initiate their first topic more quickly. The following example shows a preemptive opening where they initiate the first topic without the howareyou sequence.

\section{[Excerpt 7]}

(1) Bonnie: Hello?

(2) Yvonne: Bonnie?,

(3) Bonnie: Yeah.

(4) Yvonne: It's Yvonne.

(5) Bonnie: hhHi,

(6) Yvonne: I wanned to apologize to you for Sunday.

(Schegloff, 1986, p. 142) 
The example above shows a preemptive opening where the first topic is initiated without howareyou sequence. Yvonne could have started the howareyou sequence in (6), but instead she initiates the first topic. This can happen for various reasons which include the closeness of the relationship between the participants and the urgency of the topic. However, if a participant does not follow the basic sequences, or skips some of the sequence carelessly, miscommunication can occur. Such flaws may cause the opening section to be relatively fragile and to break down quite easily. The example below shows that a lack of the second part of an adjacency pair can interrupt the development of opening.

[Excerpt 8]

(1) Police: Police Desk (pause). Police Desk (pause). Hello, police desk (longer pause). Hello.

(2) Caller: Hello.

(3) Police: Hello (pause). Police Desk?

(4) Caller: Pardon?

(3) Police: Do you want the Police Desk?

(Schegloff, 1968, p. 1097)

The Police officer answers the call, saying, "Police Desk," in (1) but the caller does not identify him/herself as indicated in "pause," in (2) which was repeated two 
more times. The caller did not successfully provide the second part of two sequences and it resulted in miscommunication. This example shows how an opening can fall apart and how this can thus lead to miscommunication. On the other hand, the Police officer skips the greeting and howareyou sequences, but it does not lead to a miscommunication. Generally speaking, when someone calls the police, he/she need to get down to business immediately. Hence, whether a participant can skip a sequence or not is decided by social norms and expectations in certain types of discourse.

I would like to present how the howareyou sequences are conducted in Japanese because the opening sequences are different from those in English. In a Japanese telephone call, the howareyou sequence is not always present, and many other types of greeting can be used in place of the howareyou sequence. The following example is taken from Lim (2003) and involves a typical way of developing opening sequences without a howareyou sequence.

[Excerpt 9]

(1) R: もしもし

'Yes'

(2) C：あ、もしもし、X大学の Y ですけど

'Oh, hello, this is Y from X University.'

(3) R: あ、はいはいはいはい

'Oh, yes, yes, yes, yes.'

(4) C: こんにちは

'Hello.' 
(5) R: こんにちは

'Hello.'

(6) C：あのさ

'Guess what.'

(Lim, 2003, p. 44)

The excerpt [9] demonstrates that the opening in Japanese does not involve the howareyou sequence. They proceed until the greeting sequence (4) and (5) almost the same as in those in English phone call. A notable difference is the uses of “もしもし (Yes)" in the first two utterances. There are two kinds of greetings in a Japanese phone call: one is “もしもし(Yes)," which is a greeting specific to phone call and the other is general greetings such as “おはようございます (Good morning)” and “こんにちは (Hello)." The use of “もしもし(Yes)” is often observed in the second part of summon/answer sequence to confirm the availability of the answerer and sometimes of the caller. After exchanging greetings in (4) and (5), C starts the first topic instead of providing a howareyou sequence. This is one of the typical ways of opening a phone call in Japanese. In addition to skipping howareyou sequences, Japanese people often exchange phrases other than howareyou after the greeting sequence. For example, Japanese speakers often say “久しぶりですね (It’s been a while)” and “先日は失礼し ました (I'm sorry about the other day)" (Yoshino, 1994, p. 8). Thus, the opening in the Japanese phone calls involves general greetings other than howareyou. Except for the 
general greeting sequence in Japanese phone call, the basic structure of the opening sequences is similar to those in English.

What Schegloff emphasizes in his study is that opening sequences are not merely ritual and automatic expressions, so the apparent perfunctoriness can be misleading. The sequences consist of minimal adjacency pairs and if a participant fails to provide the second part of the sequence, it may cause a drastic effect on the way the opening unfolds. Participants can also skip some of the sequences, and whether this is acceptable is decided by a variety of factors. Nevertheless, a participant cannot skip part of the sequence without due reason. Therefore Schegloff claims that the fact that participants can skip some of the core sequences and interrupt the development of an opening means that the routine opening must be understood as an outcome jointly achieved by the participants (Schegloff, 1986, p. 144). Schegloff's research on openings shows that participants need to be involved in the conversation in order to open a conversation appropriately. If a participant is detached from the conversation and s/he is not able to provide what the other participant expects, the opening section could easily fall apart. Therefore, we can conclude that being involved in the interaction is important in the openings of oral conversation.

\subsection{Closings in Oral Conversation}

This section discusses the closing of oral conversations and how an intricate turntaking system is also important in developing a proper closing. First I will discuss a 
common type of closing as described by Schegloff \& Sacks (1973), and second, other variations of closings noted by another researcher (Button, 1987).

\subsubsection{Archetype closings}

Schegloff \& Sacks (1973), the first to perform an extensive analysis of the closing section, discovered that the archetype closing consists of two adjacency pairs. The first adjacency pair is the pre-closing segment and the second is the terminal exchange. The pre-closing usually consists of an adjacency pair such as "well” or "okay." One of the most important functions of a pre-closing is to show that a participant has nothing more to say and is seeking a warrant from the other participant to finish the conversation. If the hearer answers with the second part of the adjacency pair, it means that the hearer provides warrant to proceed and finish the conversation. It provides the participants with an accepted way to avoid abruptly proceeding to the terminal farewell phrases. Secondly, after they agree to close the conversation with a pre-closing, participants proceed to a terminal exchange. A terminal exchange also involves an adjacency pair such as "bye" or "see you" with which to finish a conversation. Both of these adjacency pairs, the preclosings and the terminal exchanges, constitute the entire closing section. This is a typical way of initiating closing and finishing a conversation and Button (1987) calls it "archetype closing." Below is an example of archetype closing.

[Excerpt 10]

(1) Bea: And thanks for calling 
(2) Dianna: Alright dear

(3) Bea: Alrighty

(4) Dianna: Bye

(5) Bea: $\quad$ Bye

(Button, 1987, p. 102)

Dianna's "Alright, dear" in (2) is the initial portion of the pair involved with preclosing. Bea provides the second part of the pre-closing in (3), and then both speakers mutually agree to finish the conversation by providing the terminal exchange in (4) and (5). The first adjacency pair (2) and (3) constitutes pre-closing, and the second adjacency pair (4) and (5) constitutes the terminal exchange. The four turns are the basic components of an archetype closing.

However, it should be noted that it is also possible that a participant will bring up a new topic to talk about after a pre-closing. Therefore, we do not know whether or not this type of adjacency pair is a pre-closing until it leads to a terminal exchange. For this reason, Schegloff \& Sacks state that pre-closings should properly be called "possible" pre-closings. This characteristic of a pre-closing is one of the causes of variations in the closing section. The next section will discuss other varieties of closings. 


\subsubsection{Varieties of Closings}

\subsubsection{Pre-closings with a Closing Implicative Environment}

Liddicoat (2007) observes that there are some closings with pre-closing statements that deviate from the archetype pre-closing adjacency pair. According to Liddicoat, "some particular conversational actions appear regularly as last topics in a conversation and lead to closing as a relevant future activity. These actions can be considered "closing implicative environments"” (Liddicoat, 2007, p. 259). Because this function of closing implicative environments is quite similar to the function of the first part of a pre-closing, closing implicative environments can substitute for the first part of a pre-closing. This means that a speaker can open a closing section without an adjacency pair as a pre-closing, which is different from an archetype closing. In the following example Bee verbally says in (1) that she has to leave, and it strongly implies that he would like or needs to close the conversation and it works as a closing implicative environment. Interestingly, Bee does not indicate that he has nothing to say or that their conversation is exhausted.

\section{[Excerpt 11]}

(1) Bee: W'll honey I've gotta go an get to this meeting.

(2) Dee: Okay

(3) Bee: Bye Bye

(4) Dee: Bye

(Liddicoat, 2007, p. 260) 
As shown in the example above, pre-closings do not necessarily involve an adjacency pair as long as they work to establish a closing implicative environment. Therefore, even a common type of closing requires more than merely exchanges of fixed expressions. In the next section I will discuss additional patterns of closings which will show the importance of intricate turn-taking more clearly.

\subsubsection{Re-openings: Minimal and Drastic Movement out of Closing}

The variations of closings discussed in the previous section are not particularly complicated, but Button (1987) discovered other more complicated closings. Button studied the occasions in which speakers begin a closing section but then introduce a new topic and start a new sequence without reaching a terminal exchange. Such new sequences are broken down into different sequence types such as arrangement, reasonfor-calls, and appreciations. ${ }^{5}$ Button (1987) and (1990) found that varieties in the patterns of closings can be divided into two categories: minimal movement out of closing and drastic movement out of closing. A minimal movement out of closing occurs when a participant gives a closing implicative utterance during a closing section, which is neither a pre-closing nor a terminal exchange, and the participant then comes back to the closing section again soon after the utterance. On the other hand, a drastic movement takes place when a participant gives an utterance during a closing section which is not closing

\footnotetext{
${ }^{5}$ Button (1987) includes the following "sequence types" as types that are regularly used to move out of closings: arrangement, back-references, topic initial elicitors, in-conversation objects, solicitudes, reasons-for-calls, and appreciations.
} 
implicative and then proceeds to a topic which is not relevant to the closing. Therefore a minimal movement remains in a closing framework, but a drastic movement abandons the closing section entirely. I will next discuss two sequence types which can function as drastic and minimal movements of closing.

The first sequence type I will discuss is arrangement. According to Button (1987) arrangement as a sequence type involves two features. First, the arrangement may provide a relationship between this encounter and a future encounter. Second, by mentioning a future encounter, the participant suggests that the current encounter can be concluded and further topics can be reserved for a future encounter. Therefore he also states that such arrangements may be regarded as closing implicative. Thus, participants can easily proceed to the closing section after an arrangement. The excerpt [12] below demonstrates how participants use arrangement to proceed to a closing section.

[Excerpt 12]

(1) Heather: Lemme know w't the doctor hastih sa:y.

(2) Maggie: Yeah okay well ah'll call yuh later then.

(3) Heather: Okay

$\left.\begin{array}{l}\text { (4) Maggie: Okay sweetie. } \\ \text { (5) Heather: Okay. }\end{array}\right] \quad$ (pre-closing)

$\left.\begin{array}{ll}\text { (6) Maggie: } & \text { Bye bhhye } \\ \text { (7)Heather: } & \text { Bye }\end{array}\right] \quad$ (terminal exchange) 
(Button, 1987, p. 104)

Maggie's utterance "Yeah okay well ah'll call yuh later then" in (2) fulfills the two features of arrangement which I discussed in the previous section by mentioning that she will call Heather later. The utterances "Okay sweetie" in (4) and "Okay" in (5) are considered to be a pre-closing and "Bye bhhye" in (6) and "Bye" in (7) are a terminal exchange. The participants close the conversation immediately after the arrangement without any movement out of the closing sequence.

In the next example, the participants use an arrangement as the last topic of the conversation but they minimally move out of closing.

[Excerpt 13]

$\begin{array}{ll}\text { (1) Pete: } & \text { I'll see you Tuesday. } \\ \text { (2) Marvin: } & \text { Right. }\end{array}$

(arrangement)

(3) Pete: OK Marvin.

(possible pre-closing)

(4) Marvin: You you're alright? You can get there? (overspill)

(5) Pete: Yeah. $\quad$ (answer to the overspill)

(6) Marvin: Ok

(7) Pete: Ok. Thank you.

(8) Marvin: You bet bye

(terminal exchange)

(Button, 1987, p. 108) 
In a manner similar to the previous example in excerpt [11], Pete, by uttering 'I'll see you Tuesday" in (1), talks about their future arrangement as the last topic, and Marvin says, "Right" in (2), to confirm that it is correct. Pete's utterance "OK Marvin" in (3) can be regarded as a possible pre-closing because it is the first part of a possible adjacency pair after which participants often proceed to closing as in the previous example. What is different from the previous example is that Marvin moves out of the typical sequence instead of providing the second part of a possible pre-closing. As shown in "You you're alright? You can get there?" in (4), Marvin asks a question related to the arrangement. After Pete's confirmation "Yeah" in (5), they immediately come back to the closing section and reinitiate closing. Therefore, arrangement can cause a minimal movement out of a closing.

Arrangement was used in the minimal movement out of closing in the excerpt [13], and Button (1987) also provides the term back-reference to describe one type of drastic movement out of closing. He also states that while arrangement is closing implicative, back-reference is not closing implicative because speakers can develop the conversation on the topic and closing can be suspended for a while. In the next excerpt [14] participants start to talk about a previous topic of the same conversation and in the process they drastically move out of closing

[Excerpt 14]

(1) Bea: Well I'll see you at-at. 
(2) Tess: Tomorrow night.

(3) Bea: At six, at six o'clock.

(4) Tess: Tomorrow ni - tomorrow night at six.

(5) Bea: Yeah, okay.

(6) Tess: Uh huh, and I'm sorry I didn't get Margaret, I really ve be wanting to.

(Button, 1987, p. 109)

Until line "Tomorrow ni - tomorrow night at six." in (4), Bea and Tess are talking about an arrangement for the next meeting which is often followed by a closing as shown in excerpts [12] and [13]. Bea's utterance, "okay" in (5), can be regarded as a pre-closing and it indicates that Bea has no intention of continuing and seeks a warrant from Tess to finish the conversation. However, Tess's utterance “Uh huh, and I'm sorry I didn't get Margaret, I really ve be wanting to" in (6), Tess does not provide the second part of the pre-closing. Instead she returns to the topic they were talking about earlier in the same conversation and the participants move out of closing drastically. Thus the possible closing section is no longer a closing section and they need to start another closing section in order to finish the conversation.

As discussed above, speakers minimally move out of closing in some cases, but speakers can also move completely outside the closing in other cases. After discussing the varieties of closing, Button (1987) claims that closings are very delicate parts of a conversation and the speaker must be very sensitive about whether to continue or close 
the conversation. According to Button (1987, p. 148), closings "are constituted from out of speakers' 'negotiation' with one another for continuation or closure." The study by Button (1987) shows that the closing phase is malleable, as two speakers negotiate turntaking. Closing is not something one of the speakers can achieve all by him/herself, but two of the speakers involved in the conversation have to negotiate a close to the conversation. Therefore the involvement of participants is important in the closing section just as it is in the opening section.

\subsection{Two Patterns of Closings in IM}

Closings of IM are discussed by Raclaw (2008), and he claims that there are two patterns of closings in IM. According to Raclaw (2008), the first pattern of closing in IM is expanded archetype closing, which is similar to the archetype closing of oral conversation with few differences. The second pattern is partially automated closing, which involves a part of archetype closing but is significantly different from closing in oral conversation. Before discussing Raclaw's argument, I would like to mention that the IM system Raclaw used is AIM program and participants in AIM can set an "away" message and send the message when they become "away," which means a participant is not available now. This function plays an important role in the analysis by Raclaw, so I will discuss his argument considering the effect of this function.

\subsubsection{The Expanded Archetype Closing}

Raclaw (2008) claims that expanded archetype closing has the same sequences of oral conversation closing, pre-closing and terminal exchange. What is different from the 
archetype of oral conversation closing is that expanded archetype closing in IM is followed by post-closing, which is an automated closing message sent when a participant becomes "away." Below is an excerpt with expanded archetype closing.

\section{[Excerpt 15]}

(1) fishfood: haha homework IS stupid

(2) granola: yet makes you unstupid

(3) granola: OR DOES IT

(4) fishfood: haha

(5) fishfood: okay, i'll see you tomorrow

(6) granola: ok see you then<smiles>CCCCCCCCCCCCC</smiles>

(7) fishfood: later!

(8) granola: byeeeeeeee

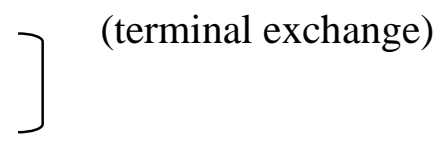

fishfood is away (automatic message) (post-closing)

(Raclaw, 2008, p. 12)

This excerpt has pre-closing and terminal exchange that are quite similar to oral conversation up to line (8), “byeeeeeeee.” Fishfood's message in (5) “okay, i'll see you tomorrow" and granola's "ok see you then" in (6) constitute an adjacency pair that works as pre-closing. Both fishfood and granola provide the terminal exchange "later!" in (7) and "byeeeeeeee" in (8) after pre-closing. These sequences are the same sequences as archetype closings in oral conversation; however, the terminal exchange is followed by 
an away message in (9). Raclaw (2008) claims that the message automatically sent after fishfood leaves constitutes a post-closing, and the post-closing message means that the conversation has truly finished. Thus, Raclaw concludes that an expanded archetype closing consists of a pre-closing, a terminal exchange and a post-closing.

However, this kind of automatic message is not always popular among many IM systems. For example Skype and Facebook IM service has a system that shows if people are online, offline, and away, but it does not send automatic message when the status changes. Moreover there is no example where participants continue communicating after terminal exchange or automatic message affects the closing sequence in Raclaw's research. Therefore I disregard post-closing in my study, and consider that conversation is finished when participants mutually provide terminal exchange. Consequently it is concluded that the first type of closing, expanded archetype closing, is considered to have the same structure as the archetype closing of oral conversation.

\subsubsection{The Partially Automated Closing}

The second type of closing in IM is partially automated closing. Raclaw (2008) claims that in this second type of closing, concrete pre-closing and terminal exchange may not be necessary. He also states that an automated message serves a central role in the closing sequence because it can finish a conversation even before terminal exchange. The automated message function makes closing of IM significantly different from archetype closing of oral conversation. Below is an example of partially automated closing. 
[Excerpt 16]

(1) sonorant: hey i have to go shower before i go out tonight.

(2) prettygirl: okay. sonorant is away (automatic message)

(Raclaw, 2008, p. 14)

In this excerpt, the participants produce a pre-closing and thus have a warrant from each other to finish the conversation, but there is no terminal exchange. The sequence of sonorant's "hey i have to go shower before i go out tonight" (1) and prettygirl's "okay" in (2) could be treated as pre-closing statements. The two messages do not constitute an adjacency pair, but "hey i have to go shower before i go out tonight" in (1) is closing implicative so that it can be included in a pre-closing. However, sonorant left the conversation without any terminal farewell phrase, and prettygirl does not provide one either. Instead of providing terminal exchange, an automatic "away" message is sent, and the conversation is finished. Even though they do not proceed to terminal exchange, sonorant leaves the conversation after prettygirl provides the second part of a pre-closing. In the next excerpt, the participant leaves without any warrant from the other participant.

\section{[Excerpt 17]}

(1) fingers: shit ive got to get to the lirary [library] like NOW befor they close

(2) girlbot: that sucks! its freezing out!!!

fingers is away (automatic message) 
(4) girlbot: call me when you're back!

(Raclaw, 2008, p. 17)

In excerpt [16], not only do both of them fail to provide terminal exchange, but they failed to give warrant to finish the conversation. Finger's message "shit ive got to get to the lirary [library] like NOW befor they close" in (1) can be considered to be a first pair part of pre-closing because it is closing implicative. However girlbot "that sucks! its freezing out!!!" in (2) provides a comment on "shit ive got to get to the lirary [library] like NOW befor they close" in (1) instead of giving a warrant to finish a conversation. Even though there is no warrant from girlbot to finish the conversation, fingers leaves the conversation with automated message (3), and there is no distinct terminal exchange. This is a significant difference from the expanded archetype closing of IM and also from oral conversation because even though there are many variations of closing a conversation, there is always warrant from each other to finish a conversation in oral communication and expanded archetype closing.

Raclaw (2008) shows that there are two variations of closing in IM. One is the expanded archetype closing, which has pre-closing and terminal exchange as in oral conversation, and the other is partially automated closing, which does not have a warrant from each participant to finish the conversation. While he discovered the two patterns of closings in IM, he does not elaborate on reasons behind the variations. I propose that the partially automated closing is closely related to the nature of the individual activity involved in IM. 
In this chapter I discussed the characteristics of spoken and written communication, and IM. I showed that the spoken and written languages are not distinct categories and there is a continuum between them, and that interpersonal involvement is one of the factors that determine if a particular type of communication is closer to spoken or written communication on this continuum. I also showed that turn-taking in IM can be characterized by the nature of individual tasks, which can be regarded as one of the characteristics of written language. Because the turn-taking systems are different, the closing sections in spoken communication and IM are also different. In the next chapter, I will reanalyze Raclaw's argument, utilizing an opening and closing segment of instant messaging from my data. I will demonstrate how the nature of interpersonal involvement in spoken communication and the nature of individual tasks in IM are observed in the differences in openings and closings between spoken communication and IM. 


\section{CHAPTER 3: DATA ANALYSIS AND DISCUSSION}

Since Raclaw's (2008) study is on closing, I will first analyze some of the features of closings in IM by using actual data from an IM conversation done in Japanese and compare the Japanese IM data and Raclaw's findings. Secondly, I will analyze the opening section of IM in my data to examine what kinds of features are found. Although the quantity of my data is limited, I will synthesize the findings in the IM opening and closing in my data and elucidate ways in which the closings and openings of IM exhibit features of both spoken and written communication.

The data that I will analyze in this section were collected from one conversation via Skype instant messaging without video. The IM service in Skype functions as follows: First, every participant needs to register with Skype and have an account. Once they establish an account, users can search for friends and add them to their friend list. The friend list shows the names of their friends and the friends' on- or offline status. The status of a participant can be seen through an icon which shows whether a participant is online, offline, busy or away. "Online" and "offline" indicate whether a participant's computer is running Skype or not. When participants are online, they can receive Skype calls and messages, but they cannot receive any calls or messages when they are offline. "Busy" means that participants are online, but they are currently engaged in something else. "Away" means that participants are online but they are away from their computer. Before participants start a conversation, they can choose who they want to talk with from their friend list. They can make a Skype call only to online participants. But they can 
send a message to either online or offline participants, even though recipients can see the messages only when they are online. They can talk to one or more people at the same time in one window. If participants change their status, the icon will change. In the Skype program, there is no away message as in the AIM system used in Raclaw's research.

When a participant sends a message, the user's Skype program will make a sound indicating that $\mathrm{s} / \mathrm{he}$ received a message. Skype will make this sound every time the users receive a message, so it is not limited to the first message.

In this study, I will analyze the IM opening and closing by using one example for each. In my data, one participant is Kenta (the author of this paper), and the other is Megumi, who is his friend. When they started the conversation, both of them were online and Megumi chose to send a message only to Kenta. They were graduate students at different universities. Both of them were using their computers in their own apartments. There was a three hour time difference because Kenta was living in Oregon and Megumi was living in Texas. Therefore, it was around 8 p.m. for Kenta and 11 p.m. for Megumi. The times shown after the utterances are the times in Oregon.

\subsection{Closing in IM}

Raclaw (2008) discovered in his data two types of closings in IM: expanded archetype closings and partially automated closings. The expanded archetype closing is similar to the sequences in oral conversation, and then followed by an automated away message. The partially automated closing is different from those utilized in oral conversation in that participants do not provide warrant, and finish the conversation with 
an automated away message. The following excerpt is a closing section from my IM data, showing features that are different from both the expanded archetype and the partially automated closing. Before the segment below, participants talked about Yamada who is a mutual friend of Megumi and Kenta. The segment starts from Megumi's message mentioning Yamada's bad habit. It is obvious that the closing in the IM from my data does not follow the archetypical closing that is typical for oral conversation.

[Excetpt 18]

(1) Megumi: いつも悪口言いたがるからね山田。[20:00] 'He always wants to speak ill of others.'

(2) Megumi: 私そろそろ健康のために寝るわ。[20:01]

'I'm going to sleep for my health.'

(3) Megumi: ケニーもちゃんと睡眠とるのよ［20:01]

'You should also get sufficient sleep, Kenny.'

(4) Megumi：おやすみー！ [20:01]

'Good night.'

(5) Kenta: まだ 11 時だろ笑[20:02]

'It is still eleven o'clock, isn't it? [symbol for laugh]'

(6) Kenta: 9 時間寝ないとだもんね！！[20:02]

'You have to sleep for nine hours, right?'

(7) Kenta: おやすみー[20:02]

'Good night.' 
As I have discussed in the literature review chapter, the closing section of an oral conversation usually involves a pre-closing and a terminal exchange, and they usually form adjacency pairs. However, the IM closing in the excerpt is different in terms of the formation of a pre-closing sequence and the positioning of adjacency pairs. The closing section seems to start with Megumi’s closing implicative utterances in “私そろそろ健康 のために寝るわ。(I'm going to sleep for my health)” in (2) and, “ケニーもちやんと 睡眠とるのよ (You should also get a sufficient sleep, Kenny).” It is true that each of Megumi's closing implicative messages receive comments from Kenta, and that these pairs of semantically related messages look like a pre-closing sequence. However, they cannot be regarded as a pre-closing sequence here because each one is not followed by a warrant. Without getting a warrant from Kenta, Megumi goes on to a terminal exchange. In addition, even though there is a terminal exchange from each participant, they are not positioned in an adjacency pair frame. Megumi provides her farewell message“おやすみ — ! (Good night!)” in (4), but her farewell is followed by Kenta's comments on Megumi’s closing implicative messages. More specifically, Kenta’s comments, “まだ 11 時だろ笑 (It is still eleven o’clock, isn’t it? [symbol for laugh]” in (5) and “9 時間寝な いとだもんね！ ! (You have to sleep for nine hours, right?)” in (6) address Megumi’s expression, “健康のために寝るわ。(I'm going to sleep for my health.)” in (2). Thus the terminal exchange in this IM conversation is not positioned in the usual adjacency pair frame. 
Because the closing in the IM from my data does not follow the archetypical closing that is typical for oral conversation, the closing section in my data might fit Raclaw's definition of a partially automated closing. However, the closings in my data do not follow the pattern of partially automated closings because there is no automated message terminating the conversation, as in partially automated closings. The question is: what are the commonalities between the closing in my data and partially automated closings, and what are the differences between the closing in my data and expanded archetype closings? I argue that the important distinction between these types of closings is whether the participants intend to be interpersonally involved in the development of the closing or the participants intend to complete the closing as individual tasks.

To reanalyze Raclaw's argument, participants in an expanded archetype closing follow the same sequences as those in oral conversation except for the automatic message, which might be the result of applying a sequence of oral conversation to IM. But I argue that the nature of interpersonal involvement plays an important role in this pattern of closing. Participants utilizing IM construct their messages as individual tasks, so each participant can basically decide when to send messages. Thus, as in the closing in my IM data, participants can send closing implicative messages and terminal messages, without waiting for the other's warrant. However in expanded archetype closing, participants send the closing implicative message first, mutually agree to finish the conversation with a pre-closing, and then provide a terminal exchange and finish the conversation. These sequences are accomplished through negotiation between participants and participants are interpersonally involved in these sequences. Participants 
in IM cannot truly interact with each other as in oral conversation because they can interact only through the screen, but the participants are nevertheless trying to be interpersonally involved in the conversation through the screen in the expanded archetype closing. Thus, I conclude that the expanded archetype closing exhibits many of the characteristics of interpersonal involvement.

However, a partially automated closing is significantly different from a closing in oral conversation because an automated message terminates the conversation without a warrant from the other participant. When a participant sends a farewell message without a warrant from the other, it means that the sender finishes the conversation because s/he wants to finish it regardless of whether the other participant wants or not. On the other hand in an oral conversation, a participant cannot leave the conversation irrespective of the other's intention. In a face-to-face conversation, leaving a conversation without a warrant and farewell message from the other participant is so rare that it is difficult to come up with a concrete example. But if it does happen, it leaves an impression that the participant who left is rude or angry, or possibly that s/he had an unavoidable and/or emergency situation and was thus compelled to leave the conversation immediately. In my study of Raclaw's discussion and my data, these negative impressions are not observed in IM conversation.

As I stated at the end of the literature review section, Raclaw's categorization of two patterns of closing lacks a detailed discussion because the distinction between expanded archetype closing and partially automated closing is no different from distinguishing the basic pattern and possible exceptions. However, based on the close 
look at the IM closing in my data, it seems that the automated away messages are not the crucial characteristics of the partially automated closing, contrary to Raclaw's findings. The IM system in Skype, which I used to collect my data, does not have such automated messages. The common characteristics found in Raclaw's partially automated closings and the closing in my data are that they do not have a warrant from each participant and participants finish the conversation regardless of the other's intention. Thus, in terms of issuance and receipt of a warrant, participants are minimally interpersonally involved in the development of the closing section. Rather, they contribute to the development of the closing individually. The construction of the closing segments without expecting warrants from the interlocutor represents one factor contributing to the nature of individual tasks. This is strikingly different from closings in oral conversation because the closings in oral conversation always have a warrant and participants do not finish a conversation without taking into account the other's intention.

Reanalyzing Raclaw (2008)'s study in conjunction with my data reveals that there are a variety of closings which exhibit mixed features of the nature of interpersonal involvement and individual activity. Proceeding to the terminal exchange without warrant from the other participant clearly means that participants are not interpersonally involved in the process of closing. At the same time, there is also a pattern of closing in IM which exhibits the nature of interpersonal involvement. When this type of closing is observed, the participants are trying to be interpersonally involved in the development of closing via limited access to the other participant. Thus the degree of interpersonal involvement 
and individual tasks varies in the closings used in IM depending on how the participants contribute to the development of closing.

I conclude that the process of closing in IM may show combinations of features of the interpersonal involvement and the individual task. These notions represent important characteristics of both spoken and written communication modes. However, I cannot definitely conclude that IM is in the middle of the continuum between spoken and written communication modes. For example, participants can type as many words as they want if there is no character limit, and messages often become long. It is quite easy to find a message longer than a hundred characters in my other IM data, as well as emails shorter than a hundred characters which are usually longer than IM. If IM messages are long, there is a low degree of spontaneity and a low frequency of exchanges between participants. In such cases, the IM conversation becomes closer to the written communication mode. On the other hand, as in the expanded archetypical closing, participants can be interpersonally involved in an IM conversation. Therefore, I conclude that IM does not have a set place in the continuum between spoken and written communication.

\subsection{Opening in IM}

If closings in IM can be divided into two categories and the distinction of the two groups can be attributed to the nature of interpersonal involvement and individual tasks, it is expected that openings in IM will exhibit features of spoken and written communication, and can be divided into two categories. One of them may be similar to 
the archetype in oral conversation, and the other may be significantly different from oral conversation because of the nature of the individual task.

The archetype of opening in phone call consists of the summons/answer sequence, an identification (and/or recognition) sequence, a greeting sequence, and one or more howareyou (How are you?) sequences. Excerpt [19] shows an opening section in my IM conversation between Megumi and Kenta. The opening section of IM in my data is significantly different from the archetype of opening in phone call. As I stated before, Skype makes a sound every time a message is received. For this analysis I have only included a record of the initial message alert tone.

[Excerpt 19] [Message Alert Tone]

(2) Megumi: ヘイ！電話番号教えて? [20:36]

'Hey! Can I have your phone number?'

(3) Kenta: わからない! ちょっと待って ! [20:36]

'I don't know! Wait a second!'

(4) Megumi: おつけ! [20:37]

'OK!'

(5) Megumi: はは[20:37]

'Haha'

(6) Kenta: 503-123-4567 [20:42]

'503 -123-4567' 
(7) Kenta: だよー[20:42]

'This is (my phone number)'

First, because participants do not call each other in IM, the summons/answer sequence in IM is different than that in a phone call, and I argue that this is because of the nature of the individual tasks. One of the important functions of the summon/answer sequence is to get attention from the answerer and confirm that the answerer is ready to talk, so the sequence usually consists of the ringing sound and a short greeting from an answerer after picking up the phone. Skype makes a sound when it receives a message and shows a symbol which indicates it has received a message. The sound and mark are considered to be summons. The reply from the answerer in IM indicates that the answerer is ready to have a conversation, and the reply is regarded as answer in IM. The sound and symbol with the first message and the reply from the answerer fulfill the functions of the summon/answer sequence, so this sequence is regarded as a summons/answer sequence in IM.

Significant differences between phone conversation and IM can be found not only in the way summon/answer sequences are achieved, but also when to provide an answer. In a phone call, an answerer picks up the phone while it is ringing, and lets the caller know that the answerer is available before the caller hangs up the phone. On the other hand, in IM, an answerer does not need to answer in a particular time, due to the nature of individual tasks. If an answerer leaves the received message unread too long, the first message sender may leave the desk or proceed to some other task, and the conversation 
may not unfold quickly. But still, it is not necessary for an answerer in IM to respond during a particular time to unfold a conversation. Of course the message receiver can respond to the first message quickly for the benefit of the first message sender, but the decision on when the receiver replies is still made by the first message receiver him/herself. The nature of individual tasks is observable in the summon/answer sequence, and the timing of the answer to the summons is dependent on the receiver's decision. The decision when to answer a summons in IM does not involve the other participant as much as the summon/answer sequence in phone call.

Second, this excerpt shows that the identification (and/or recognition) and howareyou sequence is skipped in IM opening. This might not be because of a unique characteristic of IM but because the participants know who is the other participant before they start the conversation and their frequent contact enables them to skip these sequences. Participants in phone calls in the present day can receive information about who is calling before they answer a call. Similarly, participants can see each other's names in the IM window as soon as the conversation starts. Participants can achieve identification and recognition by sending and reading the first message, and they do not have to include their names in a message. In addition to this, as Megumi and Kenta often talk or have IM conversations, they do not need to identify themselves nor had to exchange howareyous. In Japanese culture, people do not always ask how the other person is if they meet frequently as discussed in literature review chapter. So even though it is not included in the archetype structure of opening, skipping an identification and howareyou sequence can happen whether it is through IM or in a phone call. 
A part of the greeting sequence is observable in this IM excerpt, but it is significantly different from those in a phone call. The difference also reflects the nature of individual tasks. Usually in a phone call, the first part of a greeting sequence pair should be immediately followed by the second part of the adjacency pair. However, in excerpt [19] Megumi does not wait for Kenta's greeting, and she skips identification and howareyou sequences, and proceeds to the first topic in one message, “へイ! 電話番号 教えて? (Hey! Can I have your phone number?)” (1). Thus, there is no second pair part of the greeting sequence, and there is no chance for Kenta to provide the second part before Megumi proceeds to the first topic. As I will discuss later in this section, Kenta chooses to answer the first topic rather than the greeting. So the opening section in this IM conversation is achieved by Megumi alone with her greeting in the first message.

As shown, the opening in IM in my data is significantly different from the archetype of opening in an oral conversation. Then the question becomes: What accounts for the difference? I argue that the nature of the individual tasks, which are characteristics of both IM and written communication modes, is also a fundamental factor of the difference in openings between oral conversation and IM in my data.

First and foremost, Megumi presented the opening greeting along with the first topic all in the first single posting. In an oral conversation, even if a participant keeps talking as in Megumi's message (2), the other participant has a chance to jump in on the talk, produce an utterance overlapping the other participant, or to interrupt. However, because the opening section was finished before Kenta could even read the first message, there was no chance at all for Kenta to issue the second pair part of the greeting sequence 
to form an adjacency pair. Considering that the opening section is finished after Megumi's greeting, the other participant, Kenta, is not involved in the development of the opening section. What Megumi did to develop an opening section is to construct a message individually. As soon as she posts the message, the opening section is already completed. Thus the participants are not interpersonally involved in the opening section and it was completed as an individual task by one participant only.

Kenta's first message is also noteworthy. Kenta could have added the second pair part of the greeting sequence before he says “わからない!ちよっと待って！ (I don’t know! Wait a second!)," but he chose not to do so. Providing the second pair part of an adjacency pair not immediately after the first pair part is often observed in IM as discussed in the literature review section on the phantom adjacency pair. Also, in some of my other IM data, a participant greets and proceeds to the first topic, and the other answers to both parts, such as “A: よよ、いいニュースあった? (Hey, have you heard any good news?). B: よよ〜、いんたびゅーが一つありました！ (Hey, I've got one interview!)." I cannot determine if the reason Kenta disregards the greeting sequence and answers the first topic is because of the characteristics of IM or not. The omission of the greeting by the receiver can be attributed to a close relationship between the two participants, as skipping the second pair part of greeting sequence can also happen in a phone call.

However, there is an important difference between skipping the second pair of a greeting sequence in a phone call and doing so in IM. It is true that phone call may involve sequences where the first speaker provides both greeting and the first topic and 
the other provides greeting and the answer to the first topic: such as, A says "Hello. This is Tom. May I talk to John?" and B says "Hello. I'm sorry, but he is out now." It seems that providing greeting after the first topic may happen both in phone call and IM, but the difference will become obvious when the first topic becomes longer. For example, imagine a situation where a person called a restaurant to complain about the bad service, and started the phone call with "Hello. I went to your restaurant yesterday and I'm disappointed at the service because ..." Then, the answerer is unlikely to provide the second part of the greeting because the conversation has moved completely to the first topic. On the other hand in IM, I often observe cases in other IM data where a participant provides the second part of a greeting sequence after a long message about the first topic. For example, A says “ひろし！ひさしぶり！同空会の話し聞いてる？．..オレが 帰国中に一度みんなに会いたいとおもって! (Hiroshi! It's been a while! Have you heard about the reunion? . . . I would like to meet everybody while I'm in Japan!)" and B says “おっすー！久しぶり！！なんも話し聞いてねえよwwwいつ誰から聞いた あ?? (Hello! It's been a while! I haven’t heard anything about the reunion LOL. Who told you about it?)." Even if the message about the first topic becomes long as in this example, the second message sender can provide a greeting. This is because of the differences between the participant's mental protocol and the screen protocol. In IM, even if the first message sender's mental protocol has already proceeded from greeting to the first topic, the message receiver needs to focus only on the screen protocol because participants in IM do not have access to each other's mental protocol. The screen protocol still shows the message including the first pair part of greeting and the first topic, so the 
decision to greet or not is up to the answerer. The answerer can determine not only the timing of the answer to the first message, but also has more freedom to choose what to answer than in a phone call. This is because the mental protocol and screen protocol are not always the same, and an IM participant can work on message construction as an individual task depending on the nature of the screen protocol.

Even though the opening segment in excerpt [18] exhibits the nature of individual tasks and the development of the opening section is different from that in phone call, I have also observed IM openings which seem to be more similar to those in phone call. For example, A says “こんちゃーつす (Hello),” and waits for the B’s response, “ちゃー っす。鹿児島出身だったのか! 仕事がんばー (Hello. I didn’t know you are from Kagoshima! Good luck for your work).” In this example, the first message sender sends a greeting and waits for the other's greeting. While it does not follow exactly the same sequences in phone call, it seems they are more interpersonally involved in the development of IM opening than in excerpt [19] because they at least finish the greeting sequence and then proceed to the first topic. However, even in my other IM opening data, the sequences which follow all sequences of archetype opening in phone call are not observed. Thus, further research is needed to confirm if there are IM openings which follow the same sequences as those in oral conversation.

The discussion on the closing section of IM predicted that there will be features of both interpersonal involvement and individual tasks in IM openings as well. My IM opening data exhibited the features of individual tasks. The other pattern of an opening section with the nature of interpersonal involvement may or may not be found following 
further research. In this other pattern, the notion of individual tasks may not seem to be clearly observable. However, there are cases like the non-archetypical opening section of my data which was significantly different from those in oral conversation, and as predicted, it was affected by the nature of individual task. Consequently, the opening in my data exhibited the characteristics of the written communication mode, while an opening similar to those used in spoken communication seems rare although it needs to be confirmed through more thorough research.

\subsection{Continuum Among Spoken, IM and Written Communication Modes}

In the opening and closing segments of the IM data analyzed in the previous section, mixtures of spoken and written communication are observable, which can contribute to the discussion on the continuum among spoken, IM and written communication. First, the discussion on the opening and closing sections shed some light on the turn-taking system of IM. According to Beißwenger (2008), participants in IM cannot negotiate with each other because they are separated by screens and the notion of turn-taking is not totally applicable to IM because of the nature of the individual tasks. However, I argue that negotiation between participants can happen in the closings that indicate interpersonal involvement. I do not deny the fact that the participants cannot directly negotiate, and also that they cannot see the other participant's mental protocol. However, the participants in a closing that involves interpersonal aspects follow the same pattern of archetype closing in oral conversation. A participant in such closing asks if s/he can finish the conversation with a pre-closing, and the other participant has the chance to 
approve or not. After this exchange they can then proceed to the terminal exchange after their mutual agreement. These are the same negotiation processes as in the archetype closing of oral conversation. Therefore, it is true that negotiation via screen in IM is not precisely the same as that of oral conversation, but the participants in IM can negotiate with each other well enough to achieve the same function of negotiation as the in closing of oral conversation. Consequently, the turn-taking system of oral conversation can be applicable to IM to some extent if participants are interpersonally involved in the IM conversation in terms of negotiation.

In terms of the Contextualization Hypothesis by Tannen (1982), the IM excerpts in my data are similar to the spoken communication mode. The two participants had known each other for a long time before they had this IM conversation and they have a great deal of shared context. Because they have shared context, they do not need to identify each other, and they know that the other participant is doing well so they are able to skip the howareyou sequence. In addition, this close relationship means that they have a lot of shared context which allows Megumi to use a casual style from the beginning of the conversation. Thus, the Contextualization Hypothesis predicts that this segment of IM communication in my data is close to the spoken communication mode. On the other hand, it is also possible that participants in IM conversation do not know each other before the conversation. For example, some companies use IM for customer support. In such cases, participants do not have much shared context, so such IM conversation may have characteristics similar to those or written communication mode in terms of the Contextualization Hypothesis. Thus, even though further research is needed, it can be 
assumed that IM communication can be closer to either spoken or written communication mode in terms of the Contextualization Hypothesis.

In the light of Cohesion Hypothesis, Megumi’s “はは (Haha)” (4) in excerpt [19] is considered to be a cohesive device which expresses her emotion toward the content of the conversation. Megumi does not have to send this message while waiting for Kenta's reply. The main purpose of “はは (Haha)” may be to tell Kenta that she is enjoying the interchange, and lexically it does not have any other meaning for the conversation. In addition to “はは (Haha),” the use of “! ” and “?” show the participants” attitude towards the conversation. The use of " ! " usually emphasizes an emotion such as excitement, and "?" makes the sentence is a question. More interestingly, neither of them uses "。" which is the most common way to indicate the end of a sentence in written Japanese. The use of "。” is often avoided, especially among young people, because it can sound (or look) blunt, so other marks and emoticons are often used. By using these cohesion devices such as " ! " and "? ," they try to establish cohesion. Thus the Cohesion Hypothesis also predicts that this segment is closer to spoken communication, even though every cohesive device is typed out as in the written communication mode. It should be added that some IM conversation can be closer to written communication as an IM user may choose not to use non-linguistics cohesive devices. For example, as I have stated, I can find IM Japanese conversations with more than a hundred characters. In such cases, the participants may work more carefully on the organization of the text to achieve cohesion. Moreover, there are also cases where 
participants do not use cohesive devices such as "!" and "?” other than lexical items.

These cases can be regarded as being closer to written communication because the participants achieve cohesion with cohesive devices typical to written communication. This would include such methods as organization of paragraphs and altering word order. IM conversation may have characteristics of either spoken or written communication in terms of the Cohesion Hypothesis as well.

Fragmentation is another spoken characteristic found in the IM examples presented in excerpt [18] and [19]. For example in excerpt [19], Megumi types “おつけ (OK)” (3) and “はは (Haha)” (4) within one minute and both of them are related to the Kenta’s previous message “わからない！ちょっと待って! (I don’t know! Wait a second!)," so they could have been placed together in one posting. The messages in excerpt [18] of the IM closing are even more fragmented. Megumi posted four sentences in four different posts, and then, Kenta also posted three sentences in three different posts. These fragmented and spontaneous messages reflect the characteristics of spoken communication mode discussed by Chafe (1994), and these messages are considered to be similar to spoken communication. The reason why utterances are fragmented in spoken communication is that speakers encode ideas into language as they emerge in their heads, which Chafe termed the spontaneity of spoken language. On the other hand, in written communication writers can construct their message at their own pace and often look over and alter the content. This is why written communications such as books and articles are not fragmented. The fragmented messages in my IM data can be attributed to the same reasoning that explains why utterances in spoken communication are often 
fragmented. The IM messages are fragmented because Megumi typed out the messages off the top of her head without worrying about having perfect grammatical structure. This is especially clear because in excerpt [18], Megumi sent three posts within two minutes and Kenta sent four posts within only one minute. Therefore, the IM postings in my data exhibited one of the characteristics of spoken communication in terms of spontaneity.

However, this fragmentation in the IM messages can be analyzed from a different perspective than the fragmentation that is a characteristic of spoken communication. Kenta provides his phone number in (5), and separately adds “だよー (This is my phone number)" in (6), and these fragmented messages can be explained by Kenta's deliberate separation of the sentence for Megumi's convenience. Modern technology is able to recognize certain types of information, such as email addresses or phone numbers. It is also easier for the computer and the users to recognize and use the information if it is separated from other information. Because of this, information such as website addresses, email addresses, phone numbers and links to movies are often separated from other messages in written communication, especially computer-mediated communication. But it is less likely that a message that consisted solely of particular information like a phone number would be utilized in other written or computer-mediated communication as it would in IM. Thus this type of fragmented message, consisting of only particular information such as a phone number, can be considered to be a characteristic of IM. Even though this feature is not limited only to IM and it is sometimes observed in other written communication modes, it contributes to the discussion on the continuum among the spoken, IM and written communication modes. Fragmentation, which has been 
considered to be one of the characteristics of the spoken communication mode, can be observed in the written communication mode for different reasons: while spoken communication becomes fragmented because speakers make utterances as they think, fragmentation can happen in some written communication such as IM because in certain situations fragmented information is easy to recognize for both readers and computers. Fragmentation in IM can also happen because of the same reason as it does in spoken communication, as in Megumi's messages.

I analyzed the opening and closing sections of my IM data and argued that these segments exhibit properties of both written and spoken communication. The delayed placement of the second pair part of an adjacency pair and posting a greeting in conjunction with the first topic in a single posting indicate that IM is closer to characteristics of the written communication mode because of the nature of the individual tasks. On the contrary, analysis of this segment of IM in terms of the Contextualization Hypothesis and Cohesion Hypothesis showed that the segment of IM that had characteristics closer to those of spoken communication. Fragmentations are observed in the IM segment, and this is attributed to the fact that IM communication is as spontaneous as spoken communication and anticipates the need for ease of readability and recognizability for readers as it is desired in written communication. Thus, this particular segment of my IM data showed mixed characteristics of the spoken and written communication modes. Lastly, I argued that in terms of the Contextualization and Cohesion Hypotheses, the characteristics of both spoken and written communication modes can be observed in IM communication. As shown, turn-taking in closings and 
openings in IM can be closer to spoken or written communication. Thus, I conclude that IM communication can be placed in the middle of the spoken and written continuum, but the degree of closeness to spoken or written communication can vary depending on how the participants contribute to the overall conversation. While IM is closer to spoken communication when the participants are interpersonally involved through the screen, it is closer to written communication when the participants contribute to the conversation as individual tasks. 


\section{CHAPTER 4:}

CONCLUSION

The goal of this study was to investigate whether the opening and closing sections of IM are different from those found in oral communication as well as to determine what factors are responsible for the differences. To analyze the opening and closing section, I discussed the crucial characteristics that differentiate spoken language and IM and adopted Beißwenger's and Tannen's argument that IM is an individual task while oral conversation requires interpersonal involvement.

I reanalyzed Raclaw's argument on closing and discovered that the two patterns of closing he detected could be attributed to the nature of interpersonal involvement and the nature of the individual task. The detailed analysis of closing combining Raclaw's study and my IM data revealed that in the closing which utilize interpersonal involvement, the participants negotiate well enough to take turns and to finish the conversation. This occurs in a manner similar to that of oral conversation even though it occurs through screens. It is true that participants in IM can negotiate only by using information available on a screen, so the negotiations in oral conversation and IM are different as Beißwenger discusses. However, in IM closings which exhibit the nature of interpersonal involvement, the participants are able to negotiate well enough to achieve the same outcome of negotiation as it occurs in the closings of oral conversation. In such cases, the notion of turn-taking in oral conversation may be applicable to IM to some extent in terms of negotiation.

What I found in the data concerning the opening and closing sections of IM was that the opening and closing which involve the nature of the individual tasks. The 
opening section collected in my data was completed solely by one participant in only one message. In this case the other participant did not have a chance to take part in the opening section nor provide the second pair part of the greeting. Similarly, in the closing a participant finished the conversation without the other participant's warrant to finish the conversation. After a participant finished and left the conversation, the other participant provided a farewell message. Thus, both parties contributed to the development of the opening and closing sections as individual tasks. Because my data set involves only one example for each of the opening and closing, I cannot determine if these patterns of opening and closing in IM are representative of IM communication in general.

Nevertheless the opening and closing sections in my data strongly reflected the nature of the individual task in IM, and they were closer to the written communication mode in terms of turn-taking.

When I analyzed the IM opening and closing from the perspectives of the Contextualization and Cohesion Hypotheses, the IM segments exhibited characteristics closer to spoken communication. The participants' shared context enabled them to skip identification and howareyou sequences, and to use casual style from the beginning. Also, cohesive devices other than lexical items such as "!” and “笑 (symbol for laughing)" were often observed, and helped establish cohesion. These are considered to be characteristics of spoken communication in terms of the Contextualization and Cohesion Hypotheses, while turn-taking in opening and closing sections exhibited characteristics of written communication. Thus it is concluded that IM segments in my data exhibited characteristics of both spoken and written communication, and these interactions are 
considered to be a mixed mode of spoken and written communication in the light of the Contextualization and Cohesion Hypothesis.

However, IM is not only a mixed mode of spoken and written communications, but it also can be close to either spoken or written communication. The closings of IM can be closer to spoken communication when a high degree of interpersonal involvement is observed, but they can also be closer to written communication when more individual involvement is observed. Furthermore, the Contextualization and Cohesion Hypotheses predict that IM may be close to either spoken or written communication. While segments in my data showed characteristics of spoken communication because the participants had a close relationship and exchanged short messages quickly, it is conceivable that characteristics of written communication may also be detected in other cases. For example, IM communication might involve strangers exchanging longer messages in a formal setting. Therefore, I conclude that IM communication resides in the middle of the spoken and written continuum, and whether it exhibits the characteristics of spoken or written communications varies depending on the way participants contribute to the conversation. While the participants' interpersonal involvement makes IM closer to spoken communication, the participants' individualized contributions make IM closer to written communication.

As this study has shown, IM communication fluctuates between the characteristics of spoken and written communication. The participants in my data set had a casual IM conversation, but IM can be used in other situations, such as customer service or business talk. I even observe students discussing their academic papers with their friends through 
IM. I myself sometimes have serious discussion on a variety of topics with IM. It can be assumed that each type of communication via IM will exhibit different characteristics. For example, casual conversation through IM and an academic discussion through IM are likely to exhibit different characteristics. Therefore, based on the type of IM communication, there is a range for IM on the spoken-written continuum just as varieties of genres in spoken and written communication exhibit different characteristics. Thus, when analyzing IM communication, the type of communication must be taken into consideration in analyzing spoken and written communications.

Lastly, Ketcham (2011) considers computer-mediated communication to be an independent form of discourse, which does not reside in the continuum between spoken and written communication modes. He proposes a triangular continuum model which has internet discourse as one of the extremes of the continuum. Most researchers still continue to employ a continuum model which has only spoken and written communication as its extremes, but a triangular continuum model including an internet discourse extreme may be considered to be a new way to analyze diverse communication modes in the present day.

\section{Limitations of This Research}

In this study, only two instances of actual opening and closing segments in IM were used in the analyses, and each instance involved only one pattern. It is not clear how often this type of interaction would occur in a larger sampling. The opening in my IM 
data showed the nature of individual task, and it is not conclusive if it is the tendency of opening in the IM communication, thus further research is anticipated.

Second, there are some differences which depend on the participants' language and culture as Yoshino (1994) claims, so I cannot prove that this result is applicable to people who speak different languages other than Japanese. Thirdly, the level of closeness in the relationships between IM users may have a role in determining the nature of the opening and closing. For example the participants in my data knew each other, but it is also conceivable that strangers might also have a conversation through IM. If strangers use IM, I assume they will at least identify themselves. Further research on IM communication between people in different relationships may reveal different opening and closing sequences.

Third, the study only analyzed texts and did not include non-verbal aspects of interactions that occurred during the IM communication. I did not utilize many of the functions of IM, including automatic messages such as "Kenta is typing" and "Kenta read the message." Further, I could not collect data about what the participants were doing during the conversation. It is possible that the participants always gazed at the screen and the automatic message and started typing the response as soon as they read the messages from each other. The behavioral aspects of communication that occurred during the interaction would need to be incorporated into the analysis to capture the IM communication in a more accurate and thorough way.

In spite of these limitations, this research succeeded in demonstrating the nature of individual tasks and interpersonal involvement in IM, at least for the data analyzed in 
this paper. Further research is needed to confirm that the findings of this thesis are applicable to other types of IM communication, taking into the consideration such factors as relationships between IM users, purpose of IM communication, and frequency of IM communication. 


\section{REFERENCES}

Akinnaso, F. N. (1982). On the differences between spoken and written language. Language and speech, 25(2), 97-125.

Atkinson, J., \& Drew, P. (1979). Order in court. London: Macmillan.

Beißwenger, M. (2008). Situated chat analysis as window to the user's perspective: Aspects of temporal and sequential organization.Language@Internet, 5, 1-19.

Button, G. (1987). Moving out of closings. In G. Button, \& J. R. Lee (Eds.), Talk and Social Organization (pp. 101-151). Clevedon: Short Run Press.

Button, G. (1990). On varieties of closings. In G. Psathas (Ed.), Interaction competence (pp. 93-148). London and Washington D.C.: International Institute for Ethnomethodology and Conversation Analysis.

Chafe, W. (1982). Integration and involvement in speaking, writing, and oral literature. In D. Tannen (Ed.), Spoken and written language: exploring orality and literacy (pp. 35-53). Norwood: Ablex Publishing Corporation.

Chafe, W. (1994). Discourse, consciousness, and time. Chicago and London: The University of Chicago Press.

Chafe, W., \& Tannen, D. (1987). The relation between written and spoken language. Annual Review of Anthropology, 16, 383-407.

Crystal, D. (2001). Language and the internet. Cambridge: Cambridge University Press. Eggins, S. (2004). Introduction to systemic functional linguistics. New York, London: Continuum.

Garcia, A. C., \& Jacob, J. B. (1999). The eyes of the beholder: Understanding the turn- 
taking system in quasi-synchronous computer-mediated communication. Research on Language and Social Interaction, 32(4), 337-367.

Gonzalez-LLoret, M. (2011). Conversation analysis of computer-mediated communication. CALICO Journal, 28(2), 308-325.

Gumperz, J.J., Kaltman, H., \& O'Connor, M. C. (1984). Cohesion in spoken and written discourse: ethnic style and the transition to literacy. In D. Tannen (Ed.), Coherence in spoken and written discourse (pp. 3-19). Norwood, NJ: ABLEX Publishing Corporation.

Halliday, M. A. K. (1985). Spoken and written language. Oxford: Oxford University Press.

Halliday, M. A. K., \& Hasan, R. (1976). Cohesion in English. London: Longman.

Heath, S. B. (1986). 13 Critical factors in literacy development. In S. D. Castell, A. Luke, \& K. Egan, Literacy, society, and schooling (pp. 209-229). Cambridge: Cambridge University Press.

Hockett, C. F. (1960). The origin of speech. Scientific American, 203, 89-97.

Hutchby, I., \& Wooffitt, R. (1998). Conversation analysis. Cambridge: Polity Press.

Isaacs, E., Walendowski, A., Whittaker, S., Schiano, D. J., \& Kamm, C. (2002). The character, functions, and styles of IM in the workplace. In Proceedings of the 2002 ACM Conference on Computer Supported Cooperative Work (pp. 11-20). New Orleans: ACM.

Jettka, D. (2009). Speaking through keyboard? The characterization of synchronous 
chat in the continuum of spoken and written discourse. Retrieved from http://www.daniel-jettka.de/pdf/JETTKA-Speaking_through_the_keyboard.pdf

Kay, P. (1977). Language evolution and speech style. In B. Blount \& M. Sanches (Ed.), Sociocultural dimensions of language change (pp. 21-33). New York: Academic Press.

Ketcham, E. (2011). Internet discourse: the application of discourse analysis to instant messaging communication. Honors junior/senior projects. Paper 70. Retrieved from http://hdl.handle.net/2047/d20002588

Lee, N. (2005). Is the chatting between students spoken form, written form or something else? -Analysis of KWCCDLP (Korea University Waseda University Cross-Cultural Distance Learning Project) data-. In Proceedings of the 9th Conference of the Pan-Pacific Association of Applied Linguistics (pp. 132-148). Seoul: PAAL.

Levinson, S. (1983). Pragmatics. Cambridge: Cambridge University Press.

Liddicoat, A. J. (2007). An introduction to conversation analysis. London: Continuum. Lim, M. (2003). 電話会話の開始部における日韓対照研究 : 20 代の友人同士の電話 会話から [A study of Opening Dialogue in Telephone Conversations : A contrastive study of Japanese and Korean friends in their twenties]. 言語文化と 日本語教育[Language Culture and Japanese Language Teaching], 26, 41-53. Retrieved from http://hdl.handle.net/10083/50377 
Marques, G. (2008). Establishing a continuum in spoken and written language in student emails. In Systemis functional linguistics in use, 29, 564-576.

Nardi, B. A., Whittaker, S., \& Bradner, E. (2000). Interaction and outeraction: Instant messaging in action. In Proceedings of the 2000 ACM Conference on Computer Supported Cooperative Work (pp. 79-88). Philadelphia: ACM.

O’Neil, J., \& Martin, D. (2003). Text chat in action. In Proceedings of the 2003 International ACM SIGGROUP Conference on Supporting Group Work (pp. 4049). Sanibel Island: ACM.

Raclaw, J. (2008). Two patterns for conversational closings in instant message discourse. Colorado Research in Linguistics, 21(1), 1-21.

Sacks, H., Schegloff, E. A., \& Jefferson, G. (1974). A simplest systematics for the organization of turn-taking for conversation. Language, 50(4), 696-735.

Schegloff, E. A. (1968). Sequencing in conversational opening. American Anthropologist, 70(6), 1075-1095.

Schegloff, E. A. (1986). The routine as achievement. Human Studies, 9(2-3), 111-151.

Schegloff, E. A., \& Sacks, H. (1973). Opening up closings. Semantica, 8(4), 289-327.

Seedhouse, P. (2004). Conversation analysis methodology. Language Learning, 54(S1), $1-54$.

Shigemitsu, Y. (2007). A pause in conversation for Japanese native speakers: A case study of successful and unsuccessful conversation in terms of pause through intercultural communication. Academic Report. Tokyo Polytechnics University, 30(2), 11-18. 
Tannen, D. (1980). Spoken/written language and the oral/literate continuum. In Proceedings of the Sixth Annual Meeting of the Berkeley Linguistics Society, 207218.

Tannen, D. (1982). The oral/literate continuum in discourse. In D. Tannen (Ed.), Spoken and Written Language (pp. 1-16). Norwood: ABLEX Publishing Corporation.

Tannen, D. (1985). Relative focus on involvement in oral and written discourse. In D. R. Olson, N. Torrance, \& A. Hildyard (Eds.), Literacy, Language, and Learning: The Nature and Consequences of Reading and Writing (pp. 124-147). Cambridge: Cambridge University Press.

Tannen, D. (1987). The relation between written and spoken language. Annual Review of Anthropology, 16, 383-407.

Tannen, D. (1988). The commingling of orality and literacy in giving a paper at a scholarly conference. American Speech, 63(1), 34-43.

Tannen, D. (1992). How is conversation like literary discourse?: The role of imagery and details in creating involvement. In P. Downing, S. D. Lima, \& M. Noonan (Ed.), The Linguistics of Literacy (pp. 31-46). Amsterdam and Philadelphia: John Benjamins.

Tannen, D. (1997). Involvement as dialogue: Linguistic theory and the relation between conversational and literary discourse. In M. Macovski (Ed.), Dialogue and critical discourse (pp. 137-157). New York and Oxford: Oxford University.

Yoshino, A. (1994). 電話の会話におけるかけ手と受け手の言語行動 : 開始部を中 
心として [The behaviors of caller and answerer in phone conversation: focusing on opening]. 言語文化と日本語教育[Language Culture and Japanese Language Teaching], 7, 1-13. Retrieved from http://hdl.handle.net/10083/50131 